\title{
A preliminary simulation study about the impact of COVID-19 crisis on energy demand of a building mix at a district in Sweden
}

\author{
Xingxing Zhang ", Filippo Pellegrino, Jingchun Shen, Benedetta Copertaro, Pei Huang, \\ Puneet Kumar Saini, Marco Lovati
}

Department of Energy and Community Building, Dalarna University, Falun SE79188, Sweden

\section{H I G H L I G H T S}

- It simulates impact of COVID-19 on energy demand for a building mix at a district.

- Confinement scenarios are proposed based on a new district design in Sweden.

- Confinement measures increase electricity demand of buildings in the district.

- Confinement measures reduce thermal energy demand of buildings in the district.

\section{A R T I C L E I N F O}

\section{Keywords:}

COVID-19

Building

District

Energy

Demand

\begin{abstract}
A B S T R A C T
The COVID-19 outbreak is exacerbating uncertainty in energy demand. This paper aims to investigate the impact of the confined measures due to COVID-19 outbreak on energy demand of a building mix in a district. Three levels of confinement for occupant schedules are proposed based on a new district design in Sweden. The Urban Modeling Interface tool is applied to simulate the energy performance of the building mix. The boundary conditions and input parameters are set up according to the Swedish building standards and statistics. The district is at early-design stage, which includes a mix of building functions, i.e. residential buildings, offices, schools and retail shops. By comparing with the base case (normal life without confinement measures), the average delivered electricity demand of the entire district increases in a range of $14.3 \%$ to $18.7 \%$ under the three confinement scenarios. However, the mean system energy demands (sum of heating, cooling, and domestic hot water) decreases in a range of $7.1 \%$ to $12.0 \%$. These two variation nearly cancel each other out, leaving the total energy demand almost unaffected. The result also shows that the delivered electricity demands in all cases have a relatively smooth variation across a year, while the system energy demands follow the principle trends for all the cases, which have peak demands in winter and much lower demands in transit seasons and summer. This study represents a first step in the understanding of the energy performance for community buildings when they confront with this kind of shock.
\end{abstract}

\section{Introduction}

In the past few months, the COVID-19 crisis has significantly affected all aspects of our life, such as global economy, social connection, environment, and energy demand/supply. Different countries are trying various confinement measures in order to reduce the impact of such pandemic [1]. These confined measures have subsequent influence on the energy sector, which is exacerbating the energy demand issue. Steffen et al., [2] therefore highlights that it is important to navigate the new situation without jeopardizing the imperative clean energy transition under the COVID-19 outbreak.

According to the recent report [3], energy demand across Europe has fallen 'significantly' below the 2015-2019 average range in many major European markets. Unsurprisingly, the strictness of confinement measures correlates with drops in overall energy consumption at whole system level, which are about $25 \%$ in Italy, $20 \%$ in France, $12 \%$ in the UK [4]. Mcwilliams and Zachmann [5] compare the average weekday hourly electricity demand for the last few weeks to the year before, in

\footnotetext{
* Corresponding author.

E-mail address: xza@du.se (X. Zhang).
} 
which they visualize the moment when the current crisis began to have an impact on national economies and how large that impact was, from each week in 2020 with the corresponding week from 2019 for peak hours (08:00-18:00). According to their report, the average daily electricity consumption in Sweden is about $99.57 \%$ related to the same periods in 2019 in the past a few months, which shows very limited changes due to the 'soft' confinement in practice. This can be explained that on a whole system level in Sweden, the overall effect of COVID-19 could be limited due to the varying needs in different sectors. For instance, electricity demand may be reduced in transportation, industries, and commercial buildings etc, but it would rise in residential buildings. The energy demand could be in an opposite direction in an industrial district than that in a residential district. It is therefore necessary to investigate new partners and varying trends in different types of districts, so that an overall understanding on the whole energy system level can be achieved.

Moreover, the impact of COVID-19 outbreak on energy demand is largely depending on confinement measures in different countries, and cultural contexts. In general, specific consideration needs to be paid to the differences between countries, which may have different energy infrastructures, urban energy systems, occupant behaviors, confinement measures, district functions and building performance in the perspectives of geography, climate, socio-economy, culture, infrastructure, and so on. A dedicated analysis of COVID-19's impact on local energy demand is thus necessary. In addition, there might be a few more waves of COVID-19 outbreak, which may lead to different closure levels in Sweden, where the corresponding impact on Swedish energy demands in buildings stays unknown. It is thus important to have a predictive study that will help mitigate the influence from COVID-19 with appropriate pre-preparations for new policy designs that can withstand future longterm shocks [2].

Buildings at district level form up the minimum local energy infrastructure. Building performance simulation is then considered as the main approach to conduct such predictive study for energy demand in buildings. There are several classical tools that can simulate the building energy performance of a district $[6,7]$, such as CitySim, EnergyPLAN, EGIS, Urban Building Energy Models (UBEMs), Urban Modeling Interface (UMI), and City Building Energy Saver (CityBES), and other data-driven models. Among these tools, UMI is a free multi-objective modelling tool based on Rhino developed by MIT Sustainable Design Lab [8], which can evaluate the energy and environmental performance of buildings in districts and cities with respect to energy demand, walkability, daylighting potential and so on. UMI includes an application programming interface (API) for researchers to add additional performance modules and metrics. As a result, UMI is determined in this paper as the main tool to conduct the study, with validated accuracy and possibility in adding additional evaluations in the future.

The occupancy profile in buildings is a key parameter for simulation of energy demand. During the early-design stage, the classical way to estimate energy demand is based on the use of benchmarks or local standards. In this way, the occupancy density, behavior and schedule usually influence significantly on energy use in lighting, equipment and heating, ventilation and air conditioning (HVAC) systems. However, owing to the different confinement levels, the occupancy profile in buildings will be different to the conventional set up. For instance, residential energy consumptions are likely to rise when people stay longer time at home, because of both augmented conventional demand (lighting, space heating, hot water, cooking and dishwashing) and new energy demand (online meetings, computation-related workings) [9]. While offices, schools and retails will have different operation schedules by comparing to that on normal week days and weekends. As a result, the impact of COVID-19 on energy demand may be not simply similar to the difference between normal working days and weekends $[10,11]$. In fact, in most of normal cases, there are generally far fewer occupants in residential buildings during the weekdays than during weekends, so the energy demand is usually lower $[12,13]$. This cannot be expected to be the same during the COVID-19 outbreak due to the containment measures, during which people are quarantined at home to couple living and work for longer time. This means that building energy and services systems (such as HVAC, lighting, plug-loads etc.) in residential buildings have to remain operating in order to provide energy, thermal comfort and ventilation even during weekends [14]. Conversely, offices and schools will have less internal heat gains and less operation time due to less occupants and by scaling back their activities, which will result in a drop of the energy demand especially during the weekdays. Although a few studies have started to investigate the impact of new home-working mode on the energy demand, most of them have a rather small scale of target buildings, and only concentrate on potentials of demand reduction, demand shifting and 'smart' controls at homes [15] or in transportation [16] through behavior change. To the best knowledge from the authors, there is no research so far in investigating the impact of different occupancy schedules on the coupled energy demands for a large group of archetypes in a neighborhood under different confinement levels due to crisis as COVID-19 pandemic. This is driven by the unknown impact on the energy demand, as there are different variation trends for mixed buildings in a district.

In order to bridge such a research gap, this paper thus aims to investigate the impact of COVID-19 outbreak on energy demand of different buildings in a community, which consists of different archetypes, such as residential buildings, school, offices and retail shops. It proposes different occupancy schedules that represent different levels of confinement, such as normal operation, 'soft' and full lock down. With the UMI tool, the energy demand of different buildings can be then predicted in the district under different scenarios. Detailed energy variation trends for different buildings and the coupled energy demand can thus be investigated. The research results would be useful for employers, researchers, energy suppliers, policy makers and home workers themselves, to withstand future potential crisis as COVID-19 pandemic.

However, the authors would like to highlight that this paper is only an exploratory and simulation-based pilot study to understand general trends on energy demand in a mixed-use neighbourhood if occupant profiles changes due to confinements in crisis as COVID-19. It is a simulation study of a non-existing (virtual) community, which is still on design and planning stage. This paper considers the key parameters for simulation of energy demand according to the set up requirement in UMI tool, such as thermal properties of construction layers, set point temperature, occupancy density/schedule, hot water demand, ventilation system, heating/cooling system, lighting and equipment power density. While the detailed occupancy behaviour changes (e.g. power increased for TV or computer) due to COVID-19 is not addressed in this paper, which is a limitation due to lacking of existing data. The underlying occupant schedules are based on practical building regulation, historical statistics and informed assumptions. This study is a first step in the understanding of energy performance of the buildings in such a residential district when they confront with this kind of shock. It cannot reflect the influence of COVID-19 on whole energy system level, but it opens up possibilities in investigating the energy performance of buildings in other types of districts and contexts.

The whole paper is structured as followings: Section 2 briefs the research method about simulation process and definition of occupancy schedule due to COVID-19 outbreak; In section 3, the case studied is described with boundary conditions and input parameters; Section 4 presents the simulation results and the related discussion; Finally the conclusion is presented in Section 5.

\section{Simulation process and definition of occupancy schedule due to COVID-19 outbreak}

The simulation in this paper is conducted by UMI tool with the assistance of Rhino 6. Fig. 1 illustrates the simulation methodology. The first step is to import and adjust the 3D building models in Rhino 6 of the new district and then define different archetypes according to the 


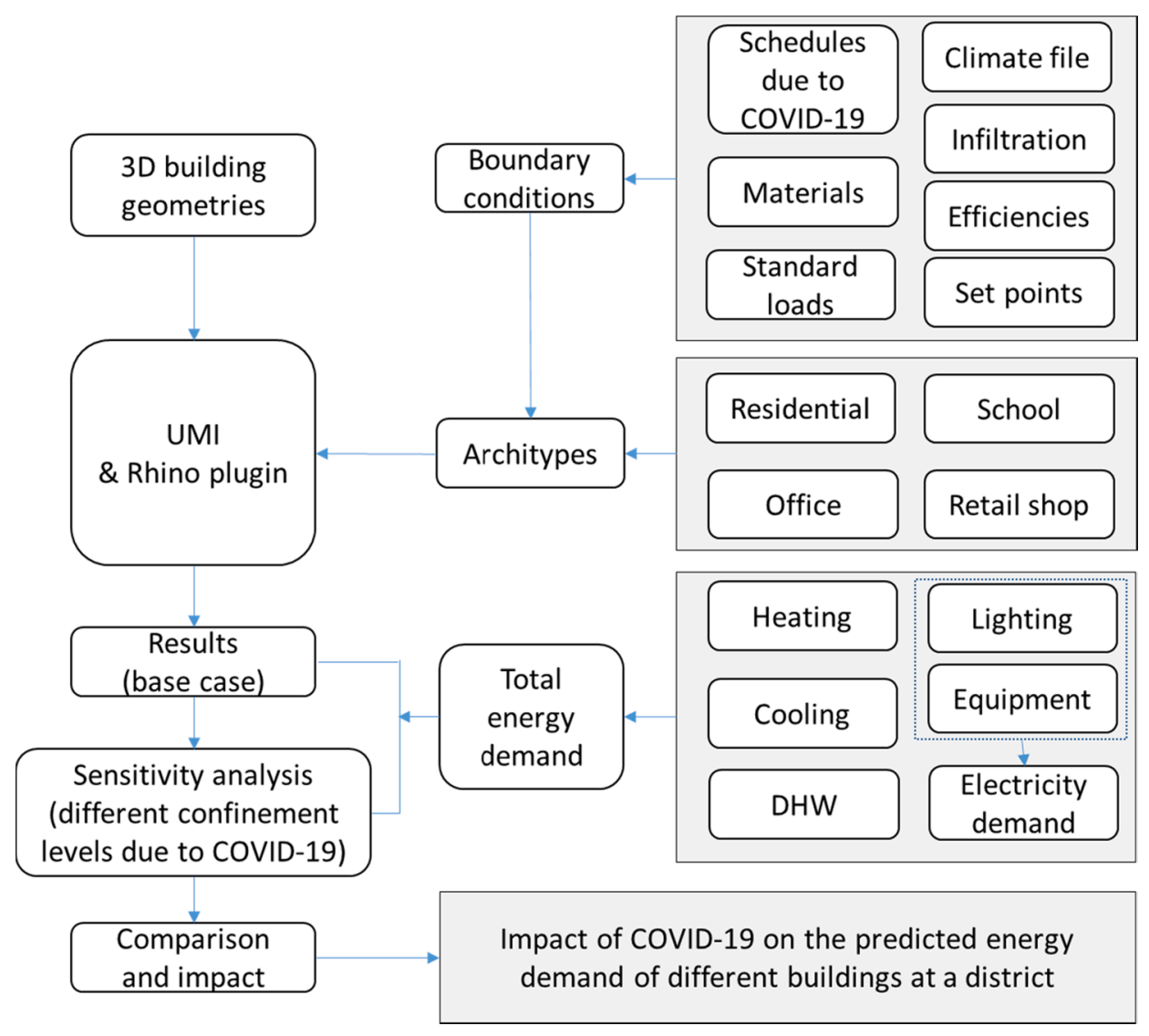

Fig. 1. Schematic of simulation method.

design. The 3D building models are further imported into UMI for simulation. A climate file can be subsequently defined and imported into the tool. Different construction layers should be defined, by choosing the materials from the UMI library and adding them into the definition when they are missing. This process needs to be done for each type of building. Afterwards, schedules for occupancy, lighting, household equipment, domestic hot water (DHW), heating, cooling and ventilation are defined according to the Swedish national regulations on building and planning during normal use in a year. Finally, since this study focuses on the simulation at early-design stage, it considers the standard simulation method and keeps the setups of other parameters (such as temperature set points, infiltration and efficiency of the heater and cooler) the same in different conditions, according to the building regulations for each building type.

The key variable in this simulation is the occupancy profile, owing to the different closure policies in case of the COVID-19 spreading. The essential considerations are the occupants density and their varying schedules in different confinement scenarios, which will affect the energy load in return. In Table 1, different confinement levels for all types of buildings are defined according to the current/possible closure policy, statistics and building regulation in Sweden. On the level 1 (no COVID19), it is considered as the base case (normal schedule) with $10 \mathrm{~h}, 14 \mathrm{~h}$, and $15 \mathrm{~h}$ unoccupied (outside of buildings) respectively in residential, school/retail shop, and office buildings. In Sweden, the building standard recommends totally 14 occupied hours (inside building), 7 days per week and 52 weeks, in a residential building per year [17]. Similar explanations can be applied to other types of buildings [18,19]. Confinement level 2 and level 3 are defined in this paper as 'soft' measures to COVID-19 outbreak. Compared to level 1, half unoccupied hours are assumed in residential, but half occupied hours are defined in other buildings except retail shops, which are considered open longer to allow citizens to have essential purchase, delivery, and pickup of food, medicine, and commodity at the special periods, but the occupancy density is reduced in order to create enough social distance. On confinement level 2, it is assumed that the unoccupied hours in residential building become half of that in level 1 , which are $5 \mathrm{~h}$ in total. This means that people are allowed to work outside of home or go out for $5 \mathrm{~h}$ per day (each $2.5 \mathrm{~h}$ in the morning and afternoon). Such confinement results in additional half hours reduce respectively in school and office building, based on the level 1 . So there will be only 5 occupied hours in school, and $4.5 \mathrm{~h}$ in office building. The schedule of retail shops is $4 \mathrm{~h}$ longer than that in level 1 . The same principle applies to the definition of level 3. While in level 4, it is considered as the full lock-down scenario, where residential buildings are occupied in $24 \mathrm{~h}$ per day but citizens are still allowed to go out for urgent or necessary food, medicine, and commodity, while school and office buildings are closed totally.

\section{Description of the new district}

\subsection{Archetype design}

The new district 'Jakobsgårdarna' locates in Borlänge city, Sweden (as shown in Fig. 2 with red colour), which is mainly a residential area but mixed with offices, retail shops and schools. All the facilities are mainly connected through walking and cycling routes [20]. The total floor areas for this district are designed at about $199016.9 \mathrm{~m}^{2}$, where residential, school, office and retail shops are $164639.0 \mathrm{~m}^{2}, 5723.4 \mathrm{~m}^{2}$, $16089.5 \mathrm{~m}^{2}$, and $12565.1 \mathrm{~m}^{2}$ respectively. There are various types of residential buildings, from single-family houses to small apartments. The residential buildings are divided in two subgroups, which differ from the structure: wood frame and masonry/concrete frame. While offices, retail shops and school are grouped, and they have the same concrete frame. The archetypes are shown in Fig. 3. This study includes total 166 buildings, in which residential buildings are plotted in red and 
Table 1

Definition of different occupancy schedules owing to the different closure policies in case of the COVID-19 spreading.

\begin{tabular}{|c|c|c|c|c|c|c|}
\hline \multirow[b]{2}{*}{ Closures ratio } & \multicolumn{2}{|l|}{ Residential Building [17] } & \multicolumn{2}{|c|}{ Educational /Commercial Building [18] } & \multicolumn{2}{|l|}{ Office Building [19] } \\
\hline & Occupancy schedule & $\begin{array}{l}\text { Scenario } \\
\text { remark }\end{array}$ & Occupancy schedule & Scenario remark & Occupancy schedule & $\begin{array}{l}\text { Scenario } \\
\text { remark }\end{array}$ \\
\hline $\begin{array}{l}\text { Level } 1 \text { (base case - no COVID-19 } \\
\text { case) }\end{array}$ & $\begin{array}{l}\text { Normal schedule (e.g. full } \\
\text { time working) ( } 14 \mathrm{~h} / 7 \mathrm{~d} / \\
52 \mathrm{w})\end{array}$ & $\begin{array}{l}10 \text { hrs } \\
\text { unoccupied }\end{array}$ & $\begin{array}{l}\text { Normal schedule (e.g. full } \\
\text { time working) }(10 \mathrm{~h} / 5 \mathrm{~d} / \\
47 \mathrm{w})\end{array}$ & 14 hrs unoccupied, & $\begin{array}{l}\text { Normal schedule (e.g. full } \\
\text { time working) }(9 \text { h/5d/ } \\
47 w)\end{array}$ & $\begin{array}{l}15 \mathrm{hrs} \\
\text { unoccupied }\end{array}$ \\
\hline $\begin{array}{l}\text { Confinement level } 2 \text { (compared } \\
\text { to level 1, half unoccupied } \\
\text { hours in residential, but half } \\
\text { occupied hours in other } \\
\text { buildings) }\end{array}$ & $\begin{array}{l}2.5 \mathrm{hr} \text { free on the morning } \\
\text { and } 2.5 \mathrm{hr} \text { free on the } \\
\text { afternoon for part time } \\
\text { work }(19 \mathrm{~h} / 7 \mathrm{~d} / 52 \mathrm{w})\end{array}$ & $\begin{array}{l}5 \text { hrs } \\
\text { unoccupied }^{1}\end{array}$ & $\begin{array}{l}3.5 \mathrm{hr} \text { free on the } \\
\text { morning and } 3.5 \mathrm{hr} \text { free } \\
\text { on the afternoon for part } \\
\text { time work }(5 \mathrm{~h} / 5 \mathrm{~d} / 47 \mathrm{w})\end{array}$ & $\begin{array}{l}19 \text { hrs unoccupied; } \\
\text { Retail shops open } \\
\text { longer }^{2}\end{array}$ & $\begin{array}{l}3.5 \mathrm{hr} \text { free on the } \\
\text { morning and } 4 \mathrm{hr} \text { free on } \\
\text { the afternoon for part } \\
\text { time work }(4.5 \mathrm{~h} / 5 \mathrm{~d} / \\
47 \mathrm{w})\end{array}$ & $\begin{array}{l}19.5 \mathrm{hrs} \\
\text { unoccupied }\end{array}$ \\
\hline $\begin{array}{l}\text { Confinement level } 3 \text { (compared } \\
\text { to level } 2 \text {, half unoccupied } \\
\text { hours in residential, but half } \\
\text { occupied hours in other } \\
\text { buildings) }\end{array}$ & $\begin{array}{l}1 \mathrm{hr} \text { free on the morning } \\
\text { and } 1.5 \mathrm{hr} \text { free on the } \\
\text { afternoon }(21.5 \mathrm{~h} / 7 \mathrm{~d} / \\
52 \mathrm{w})\end{array}$ & $\begin{array}{l}2.5 \mathrm{hrs}^{1} \\
\text { unoccupied }^{1}\end{array}$ & $\begin{array}{l}1.5 \mathrm{hr} \text { free on the } \\
\text { morning and } 2 \mathrm{hr} \text { free on } \\
\text { the afternoon }(2.5 \mathrm{~h} / 5 \mathrm{~d} / \\
47 \mathrm{w})\end{array}$ & $\begin{array}{l}21.5 \text { hrs } \\
\text { unoccupied; Retail } \\
\text { shops open longer } \\
2\end{array}$ & $\begin{array}{l}1.75 \mathrm{hr} \text { free on the } \\
\text { morning and } 2 \mathrm{hr} \text { free on } \\
\text { the afternoon }(2.25 \mathrm{~h} / 5 \mathrm{~d} / \\
47 \mathrm{w})\end{array}$ & $\begin{array}{l}21.75 \mathrm{hrs} \\
\text { unoccupied }\end{array}$ \\
\hline Confinement level 4 & $\begin{array}{l}24 \mathrm{hr} \text { at home }(24 \mathrm{~h} / 7 \mathrm{~d} / \\
52 \mathrm{w})\end{array}$ & $\begin{array}{l}\text { Fully stay at } \\
\text { home }^{3}\end{array}$ & School is closed & $\begin{array}{l}\text { Retail shops open } \\
\text { longer }^{2}\end{array}$ & Fully closed & Full closure \\
\hline
\end{tabular}

\footnotetext{
${ }^{1}$ During the confinement scenarios , all plugging equipment schedules are proportional to respective occupancy schedules.

2 Retail shops are supposed open longer for urgent and necessary purchase, delivery, and pickup of food, medicine, and commodity;

${ }^{3}$ Citizens are still allowed to go out for occasionally necessary food, medicine, and commodity.
}

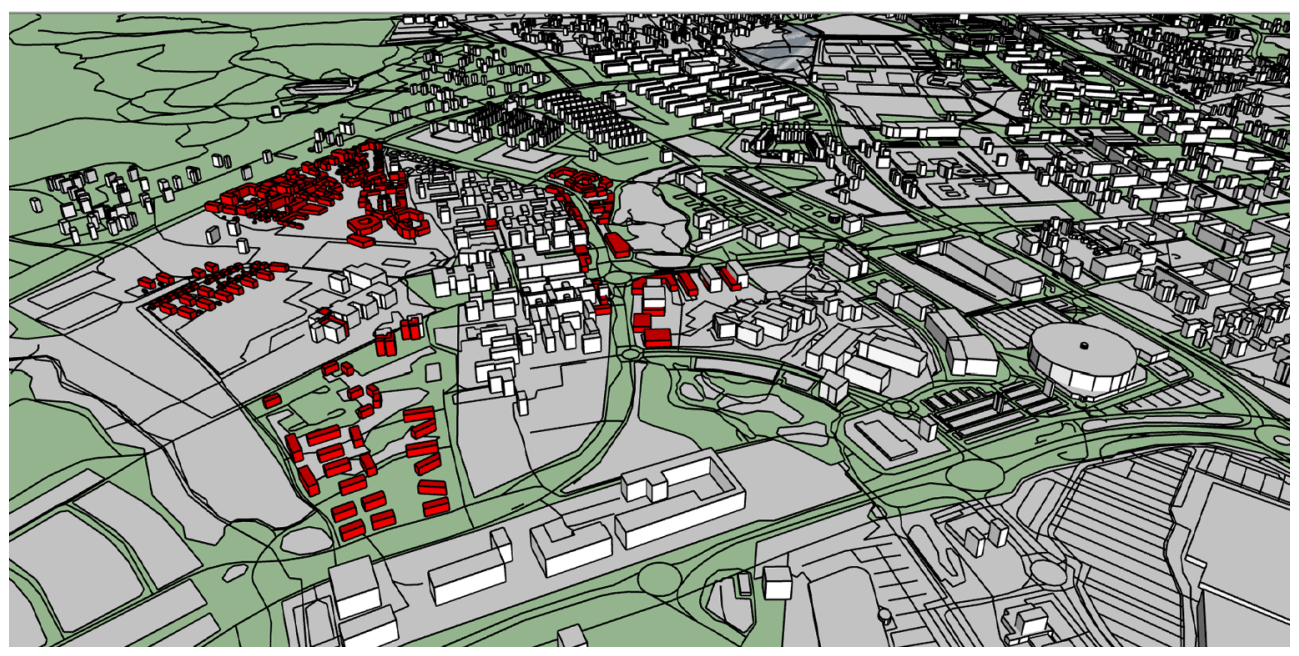

Fig. 2. 3D view of Borlänge city, in which red blocks showing the studied Jakobsgårdarna area.

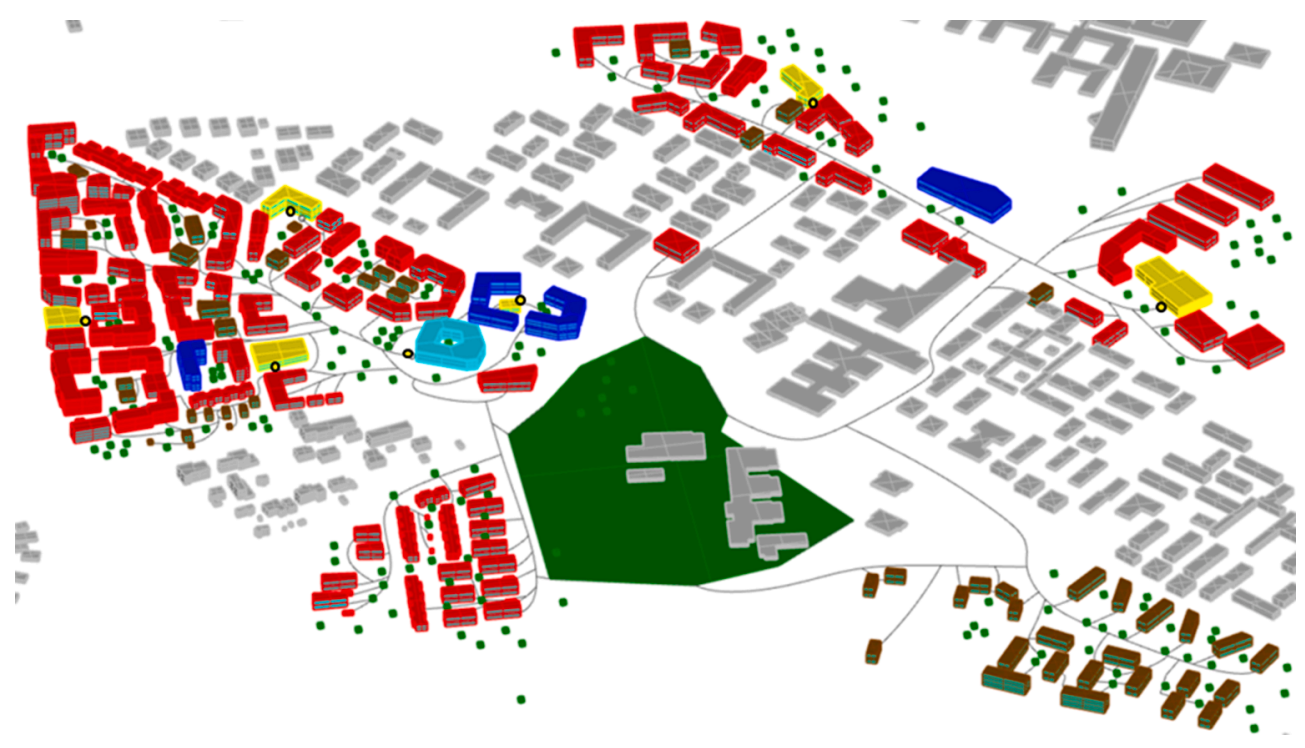

Fig. 3. 3D view of the investigated district with surrounding information. 
brown, offices are in blue, retail premises are in yellow and the school is in cyan.

The structures for buildings in this district are defined as three groups as explained above. In UMI tool, the construction layers consist of façade, ground floor, interior floor, partition and roof. Regarding the wood frame, plywood and softwood are the two main components, and standard fiberglass is selected as insulation layer for the façades and the roof, while the extruded polystyrene (XPS) panel is used for the ground floor. The façade has an air gap of $3 \mathrm{~cm}$ to prevent condensation issues and to remove excess moisture. The masonry structure is made by clay bricks, an air gap of $3 \mathrm{~cm}$ and concrete block of $15 \mathrm{~cm}$. In this case, the insulation layer is considered as XPS in all the structure except for the roof, where there is fiberglass that is lighter without too much weight load. The concrete structure for offices, retail shops and the school is simply configured by concrete blocks, XPS as insulation layer and cladding inside and outside. In the latter case, the roof is designed with light concrete and fiberglass as insulation. The whole buildings in this district are designed by triple glazed windows with air between panels and treated with low-emission coating. The thermal properties and the related U-values are then calculated for all the structures to meet local building requirements [21], which are summarized in Table 2 and Table 3 for residential buildings and rest buildings respectively. Fig. 3 also illustrates the categorization of wooden (brown highlighted) and masonry buildings (red highlighted) in the district.

\subsection{Climate analysis}

The simulation work is carried out using the climate file of Borlänge city, Sweden, which is derived from the national statistics [22]. From weather information collected from Figs. 4-6, the climate is characterized with freezing winter and pleasantly warm summers in general. During the winter, the average external air temperature drops below freezing $\left(0^{\circ} \mathrm{C}\right)$ from late October and reaches the lowest temperature in early spring. Summer starts from June to August, which is a mild season with more sunny days. Extreme hot temperatures are recorded rarely: occasionally the external air temperature can reach $28^{\circ} \mathrm{C}$ within historic records. There is an obvious diurnal temperature variation along with
Table 3

Thermal properties of construction layers in offices/shops/school according to standard [16]

\begin{tabular}{llll}
\hline Concrete & & & \\
\hline Façade & $\begin{array}{l}\text { Thickness, } \\
\mathrm{d}(\mathrm{m})\end{array}$ & $\begin{array}{l}\text { Conductivity, } \mathrm{k} \text { [W/ } \\
\mathrm{mK}]\end{array}$ & $\begin{array}{l}\text { R-value d/k } \\
{[\mathrm{m} 2 \mathrm{~K} / \mathrm{W}]}\end{array}$ \\
\hline Vinyl_cladding & 0.005 & 0.16 & 0.031 \\
XPS_board & 0.3 & 0.037 & 8.108 \\
Concrete_block_H & 0.15 & 1.25 & 0.12 \\
Gypsum_plaster & 0.003 & 0.42 & 0.007 \\
Total & 0.458 & $\mathrm{R}_{\text {tot }}$ & 8.437 \\
& & $\mathrm{U}-\mathrm{value})[\mathrm{W} / \mathrm{m} 2 \mathrm{~K}]$ & $\mathbf{0 . 1 1 9}$ \\
Roof & Thickness, & Conductivity, $\mathrm{k}[\mathrm{W} /$ & $\mathrm{R}-\mathrm{value} \mathrm{d} / \mathrm{k}$ \\
& $\mathrm{d}(\mathrm{m})$ & $\mathrm{mK}]$ & {$[\mathrm{m} 2 \mathrm{~K} / \mathrm{W}]$} \\
\hline Ceramic_tile & 0.02 & 0.8 & 0.025 \\
Concrete_MC_light & 0.05 & 1.65 & 0.030 \\
Fiberglass_batts & 0.35 & 0.043 & 8.140 \\
Air_floor_15cm & 0.15 & 0.7 & 0.214 \\
Gypsum_board & 0.015 & 0.16 & 0.094 \\
Total & 0.585 & $\mathrm{R}_{\text {tot }}$ & 8.673 \\
& & $\mathrm{U}-\mathrm{value}\left[\mathrm{W} / \mathrm{m}^{2} \mathrm{~K}\right]$ & $\mathbf{0 . 1 1 5}$ \\
Ground & Thickness (m) & $\mathrm{k}[\mathrm{W} / \mathrm{mK}]$ & $\mathrm{R} \mathrm{d} / \mathrm{k}[\mathrm{m} 2 \mathrm{~K} / \mathrm{W}]$ \\
\hline Concrete_RC_dense & 0.2 & 1.75 & 0.114 \\
XPS_board & 0.25 & 0.037 & 6.757 \\
Concrete_MC_light & 0.07 & 1.65 & 0.042 \\
Cement_mortar & 0.08 & 0.8 & 0.1 \\
Ceramic_tile & 0.02 & 0.8 & 0.025 \\
Total & 0.62 & $\mathrm{R}_{\text {tot }}$ & 7.168 \\
& & $\mathrm{U}-\mathrm{value}\left[\mathrm{W} / \mathrm{m}^{2} \mathrm{~K}\right]$ & $\mathbf{0 . 1 3 9}$ \\
\hline
\end{tabular}

greater windy occasions. Sometimes, it can be very cool, or even cold at night, since the external air temperature can drop below $10^{\circ} \mathrm{C}$ even in summer. Due to its northern latitude, the days are very short during winter season and the amount of solar radiation resource is valuable with the maximum daily total of direct normal radiation lower than $3000 \mathrm{Wh} / \mathrm{m}^{2}$ per day. In terms of wind condition, the annual wind velocity is around $2.5 \mathrm{~m} / \mathrm{s}$, presenting pleasant light breeze. The prevalent wind directions are from 225 (Southwest) and 292.5 (Northwest).

Table 2

Thermal properties of construction layers in residential building according to standard [21]

\begin{tabular}{|c|c|c|c|c|c|c|c|}
\hline \multicolumn{4}{|l|}{ Wood } & \multicolumn{4}{|l|}{ Masonry } \\
\hline Façade & $\begin{array}{l}\text { Thickness, } \\
\mathrm{d}(\mathrm{m})\end{array}$ & $\begin{array}{l}\text { Conductivity, } \mathrm{k} \text { [W/ } \\
\mathrm{mK}]\end{array}$ & $\begin{array}{l}\text { R-value } \mathrm{d} / \mathrm{k}\left[\mathrm{m}^{2} \mathrm{~K} /\right. \\
\mathrm{W}]\end{array}$ & Façade & $\begin{array}{l}\text { Thickness, } \\
\mathrm{d}(\mathrm{m})\end{array}$ & $\begin{array}{l}\text { Conductivity, k [W/ } \\
\mathrm{mK}]\end{array}$ & $\begin{array}{l}\text { R-value } \mathrm{d} / \mathrm{k}\left[\mathrm{m}^{2} \mathrm{~K} /\right. \\
\mathrm{W}]\end{array}$ \\
\hline Softwood_general & 0.03 & 0.13 & 0.231 & Clay_brick_H & 0.06 & 0.41 & 0.146 \\
\hline Air_wall_3cm & 0.03 & 0.1 & 0.3 & Air_wall_3cm & 0.03 & 0.1 & 0.3 \\
\hline Fiberglass_batts & 0.3 & 0.043 & 6.977 & XPS_board & 0.3 & 0.037 & 8.108 \\
\hline Plywood_board & 0.03 & 0.11 & 0.273 & Concrete_block_H & 0.15 & 1.25 & 0.12 \\
\hline Gypsum_board & 0.015 & 0.16 & 0.094 & Gypsum_plaster & 0.003 & 0.42 & 0.007 \\
\hline Total & 0.405 & $\mathrm{R}_{\text {tot }}$ & 8.044 & Total & 0.543 & $\mathrm{R}_{\text {tot }}$ & 8.852 \\
\hline Roof & $\begin{array}{l}\text { Thickness, } \\
\mathrm{d}(\mathrm{m})\end{array}$ & $\begin{array}{l}\mathrm{U} \text {-value }\left[\mathrm{W} / \mathrm{m}^{2} \mathrm{~K}\right] \\
\text { Conductivity, } \mathrm{k}[\mathrm{W} / \\
\mathrm{mK}]\end{array}$ & $\begin{array}{l}0.124 \\
\text { R-value d/k }\left[\mathrm{m}^{2} \mathrm{~K} /\right. \\
\mathrm{W}]\end{array}$ & Roof & $\begin{array}{l}\text { Thickness, } \\
\mathrm{d}(\mathrm{m})\end{array}$ & $\begin{array}{l}\text { U-value }[\mathrm{W} / \mathrm{m} 2 \mathrm{~K}] \\
\text { Conductivity, k [W/ } \\
\mathrm{mK}]\end{array}$ & $\begin{array}{l}\mathbf{0 . 1 1 3} \\
\text { R-value } \mathrm{d} / \mathrm{k}\left[\mathrm{m}^{2} \mathrm{~K} /\right. \\
\mathrm{W}]\end{array}$ \\
\hline Ceramic_tile & 0.02 & 0.8 & 0.025 & Ceramic_tile & 0.02 & 0.8 & 0.025 \\
\hline Plywood_board & 0.03 & 0.11 & 0.273 & Concrete_MC_light & 0.05 & 1.65 & 0.030 \\
\hline Fiberglass_batts & 0.35 & 0.043 & 8.140 & Fiberglass_batts & 0.35 & 0.043 & 8.140 \\
\hline Air_floor_15cm & 0.15 & 0.7 & 0.214 & Air_floor_15cm & 0.15 & 0.7 & 0.214 \\
\hline Gypsum_board & 0.015 & 0.16 & 0.094 & Gypsum_board & 0.015 & 0.16 & 0.094 \\
\hline Total & 0.565 & $\mathrm{R}_{\text {tot }}$ & 8.915 & Total & 0.585 & $\mathrm{R}_{\text {tot }}$ & 8.673 \\
\hline Ground & $\begin{array}{l}\text { Thickness, } \\
\mathrm{d}(\mathrm{m})\end{array}$ & $\begin{array}{l}\mathrm{U} \text {-value }\left[\mathrm{W} / \mathrm{m}^{2} \mathrm{~K}\right] \\
\text { Conductivity, } \mathrm{k}[\mathrm{W} / \\
\mathrm{mK}]\end{array}$ & $\begin{array}{l}\mathbf{0 . 1 1 2} \\
\text { R-value } \mathrm{d} / \mathrm{k}\left[\mathrm{m}^{2} \mathrm{~K} /\right. \\
\mathrm{W}]\end{array}$ & Ground & $\begin{array}{l}\text { Thickness, } \\
\mathrm{d}(\mathrm{m})\end{array}$ & $\begin{array}{l}\mathrm{U} \text {-value }\left[\mathrm{W} / \mathrm{m}^{2} \mathrm{~K}\right] \\
\text { Conductivity, } \mathrm{k}[\mathrm{W} / \\
\mathrm{mK}]\end{array}$ & $\begin{array}{l}\mathbf{0 . 1 1 5} \\
\text { R-value d/k }\left[\mathrm{m}^{2} \mathrm{~K} /\right. \\
\mathrm{W}]\end{array}$ \\
\hline Concrete_RC_dense & 0.2 & 1.75 & 0.114 & Concrete_RC_dense & 0.2 & 1.75 & 0.114 \\
\hline XPS_board & 0.25 & 0.037 & 6.757 & XPS_board & 0.25 & 0.037 & 6.757 \\
\hline Concrete_MC_light & 0.07 & 1.65 & 0.042 & Concrete_MC_light & 0.07 & 1.65 & 0.042 \\
\hline Cement_mortar & 0.08 & 0.8 & 0.1 & Cement_mortar & 0.08 & 0.8 & 0.1 \\
\hline Ceramic_tile & 0.02 & 0.8 & 0.025 & Ceramic_tile & 0.02 & 0.8 & 0.025 \\
\hline \multirow[t]{2}{*}{ Total } & 0.62 & $\mathrm{R}_{\text {tot }}$ & 7.168 & Total & 0.62 & $\mathrm{R}_{\text {tot }}$ & 7.168 \\
\hline & & U-value) $\left[\mathrm{W} / \mathrm{m}^{2} \mathrm{~K}\right]$ & 0.139 & & & U-value $\left[\mathrm{W} / \mathrm{m}^{2} \mathrm{~K}\right]$ & 0.139 \\
\hline
\end{tabular}




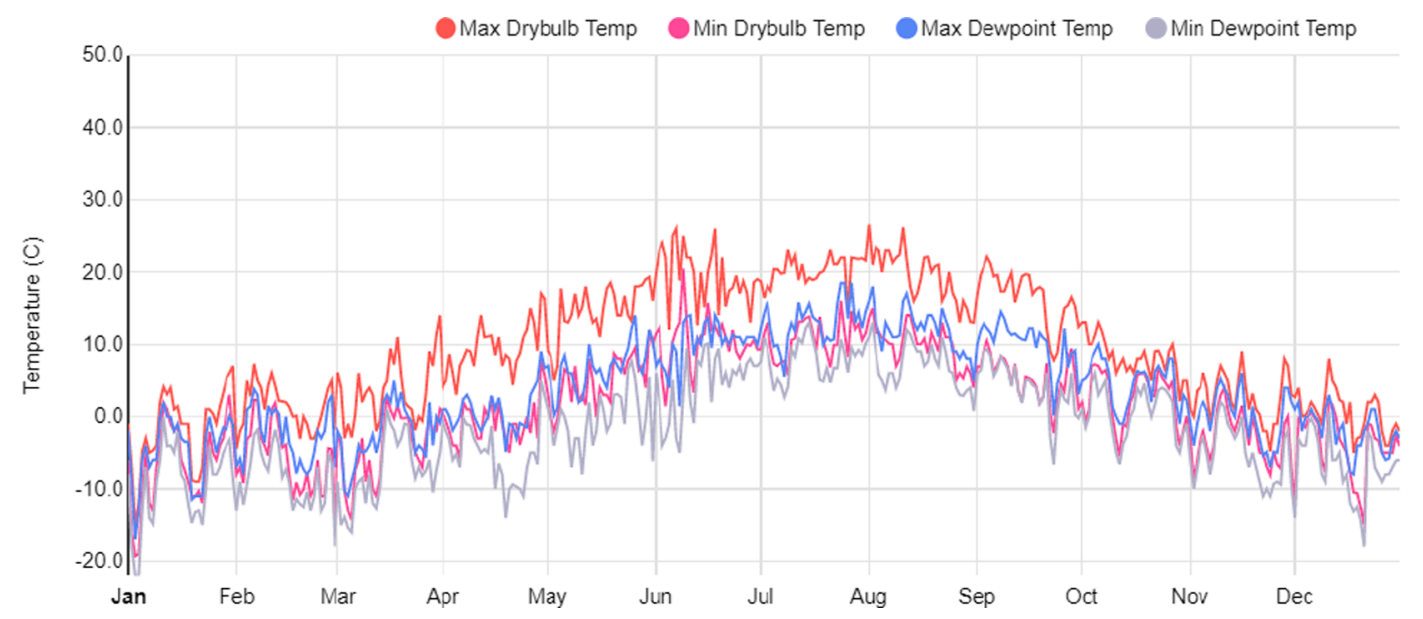

Fig. 4. Daily maximum and minimum external air temperature in Borlänge, Sweden [22]

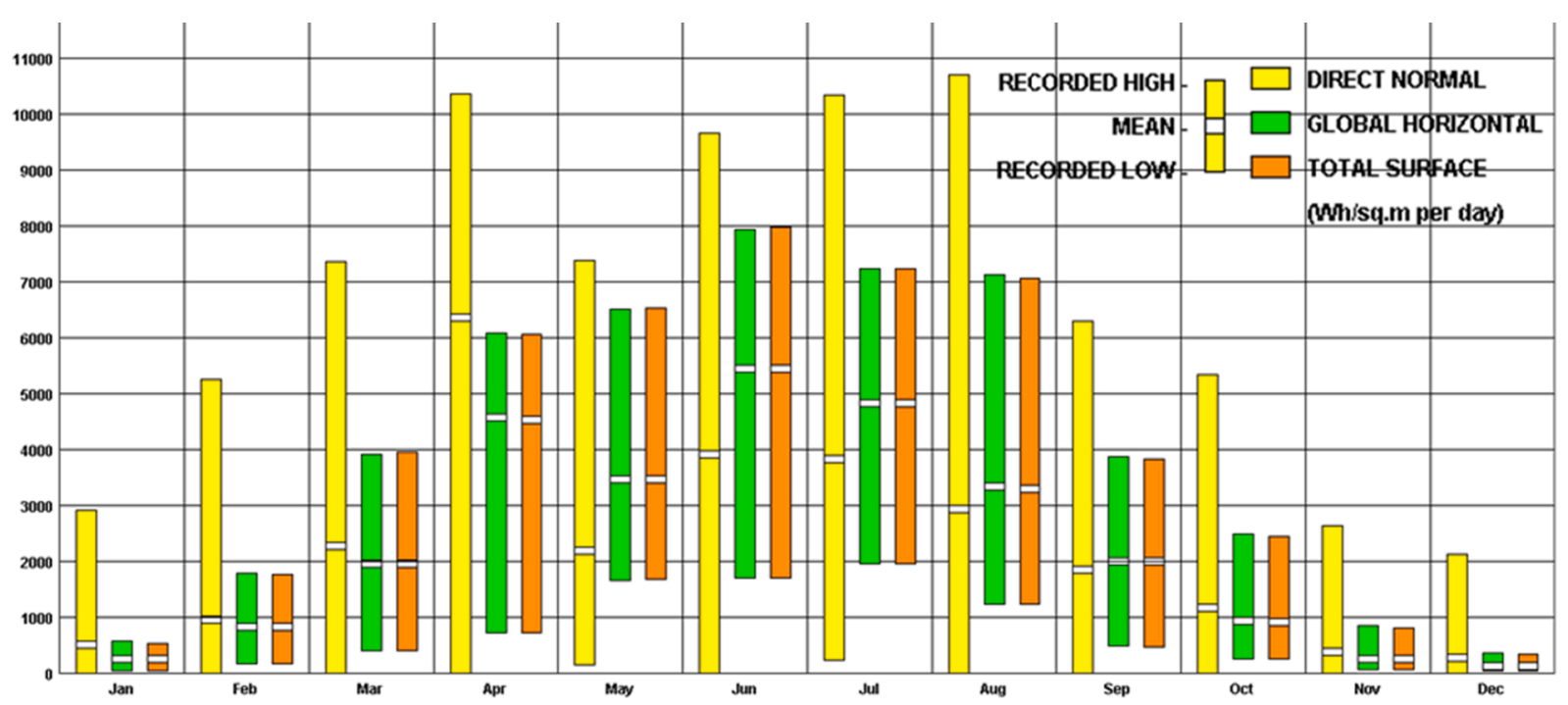

Fig. 5. Daily total solar radiation profile in Borlänge, Sweden [22]

\subsection{Boundary conditions and parameters set up}

In order to perform the simulation as accurate as possible, the key parameters need to be set up in the tool. For each archetype, it is necessary to define standard electricity loads, air conditioning, windows type and DHW load. These input data are chosen carefully according to the SVEBY ("Standardize and verify energy performance" in Sweden) for residential building [17], school [18] and commercial building [19], or with reasonable assumptions where needed as suggested from the national building standards $\left(\mathrm{BBR}^{1} 26\right.$ and $\mathrm{BFS}^{2} 2016: 12 \mathrm{BEN}^{3}$ in Sweden $[21,23])$, as well as the recommendation from industry. We assume the simulation is based on one year duration. It is practical because there might be different waves of the virus, and we may have to maintain the confinement measures for a long time. Table 4 summarizes of boundary conditions and key parameters set up.

\footnotetext{
${ }^{1}$ BBR stands for 'Boverkets byggregler' in Swedish, which means the National Board of Housing, Building and Planning for building regulations

2 BFS represents the collection of statutes at the National Board of Housing, Building and Planning.

${ }^{3}$ BEN stands for 'Byggnadens Energianvändning' in Swedish, which means Building Energy Use.
}

\subsubsection{Residential buildings}

The residential buildings accounts for a large proportion in this district and it is important to define the input data carefully. Both wood and masonry structures are considered the same parameters.

The standard electricity loads include with occupancy density, equipment power density and lighting density per square meter. The occupancy density for residential buildings is defined by national building standard (BFS 2016:12 BEN [23]) based on how many rooms and kitchens there will be in the building. Since this design is still at the early stage, there is no detailed information about the interior design of each building. It is thus considered $20 \mathrm{~m}^{2}$ for each room and $5 \mathrm{~m}^{2}$ for the kitchen in total. So each person has $25 \mathrm{~m}^{2}$. By converting it in person/ $\mathrm{m}^{2}$, the occupancy density will be 0.04 person $/ \mathrm{m}^{2}$. The equipment and lighting power density are considered to be $8 \mathrm{~W} / \mathrm{m}^{2}$ in total. The BFS 2016:12 BEN1 [21] suggests $30 \mathrm{kWh} /\left(\mathrm{m}^{2}\right.$ year) for the household electricity (equipment and lighting) [23], which is about $3.5 \mathrm{~W} / \mathrm{m}^{2}$ that is smaller than the $8 \mathrm{~W} / \mathrm{m}^{2}$ considered. However, the power density will be depended on specific schedule as defined in Table 1 , so the power system is not always on, which will result in a closer power density to the standard. Moreover, according to the Swedish Internet Foundation [24], more than two thirds of Swedes already work online from home for certain time, with around a third doing this on a daily or weekly basis. Depending on the survey from 2009 to 2018 , about $48 \%$ companies allowed employees working from home in average [25]. The existing 


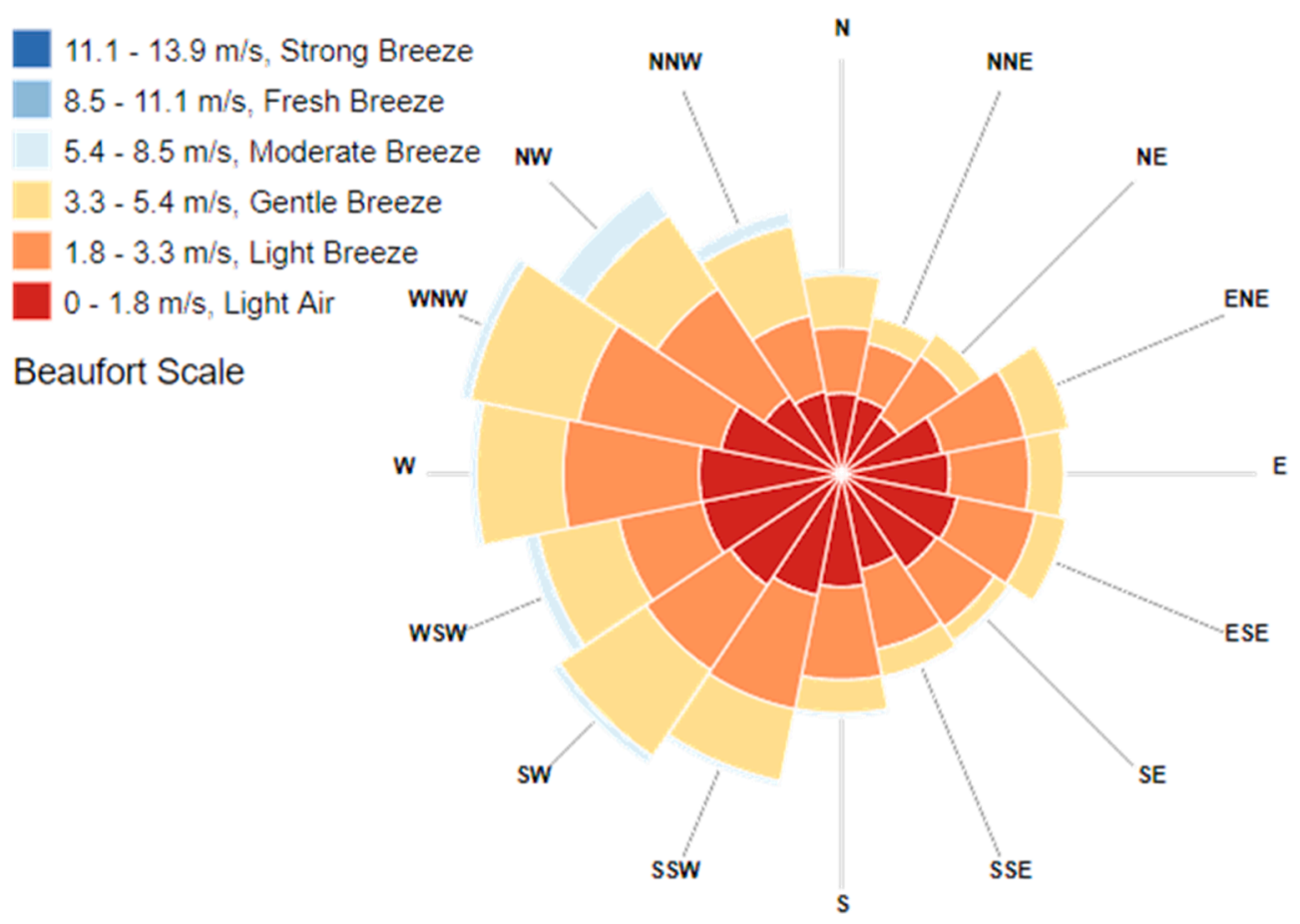

Fig. 6. Monthly mean wind speed profile and wind rose in Borlänge, Sweden [22]

Table 4

Summary of the boundary conditions and key parameters set up.

\begin{tabular}{|c|c|c|c|c|}
\hline & Residential & Office & School & Retail \\
\hline Set point temperature $[\mathrm{C}]$ & 21 & 21 & 22 & 21 \\
\hline Occupancy density [person $/ \mathrm{m}^{2}$ ] & 0.04 & 0.05 & 0.067 & 0.3 \\
\hline Occupancy schedule & Figure 7, a1\&a2 & Figure $7, \mathrm{~b} 1 \& \mathrm{~b} 2$ & Figure $7, \mathrm{~d} 1 \& \mathrm{~d} 2$ & Figure $7, \mathrm{c} 1 \& \mathrm{c} 2$ \\
\hline \multicolumn{5}{|l|}{ DHW } \\
\hline Hot water annual demand $\left[\mathrm{kWh} / \mathrm{m}^{2}\right]$ & 25 & 2 & 2 & 2 \\
\hline \multicolumn{5}{|l|}{ Ventilation } \\
\hline Infiltration ACH & 0.05 & 0.05 & 0.05 & 0.05 \\
\hline Mechanical ventilation & yes & yes & yes & yes \\
\hline Min fresh air per area $\left[1 / \mathrm{s} / \mathrm{m}^{2}\right]$ & 0.35 & 0.13 & 0.25 & 0.23 \\
\hline Min fresh air per person [1/s/person] & 0.7 & 0.7 & 0.7 & 0.7 \\
\hline Heat recovery type sensible efficiency & 0.8 & 0.8 & 0.8 & 0.8 \\
\hline \multicolumn{5}{|l|}{ Conditioning } \\
\hline Heating set point [C] & 21 & 21 & 22 & 21 \\
\hline Heating COP & 1 & 1 & 1 & 1 \\
\hline Heating schedule & \multicolumn{4}{|c|}{ All day on from 1st Oct. to 30th Apr. } \\
\hline Cooling set point $[\mathrm{C}]$ & - & 26 & 26 & 26 \\
\hline Cooling COP & 3 & 3 & 3 & 3 \\
\hline \multirow[t]{2}{*}{ Cooling schedule } & \multicolumn{4}{|c|}{ Cooling season is from 15th May. to 31th Aug. } \\
\hline & - & Figure 7, b7 & Figure $7, \mathrm{~d} 7$ & Figure 7, c7\&c8 \\
\hline \multicolumn{5}{|l|}{ Standard Loads } \\
\hline Equipment $\left[\mathrm{W} / \mathrm{m}^{2}\right]$ & 4 & 10 & 8 & 7 \\
\hline Equipment schedule & Figure 7, a5\&a6 & Figure 7, b5\&b6 & Figure 7, d5\&d6 & Figure 7, c5\&c6 \\
\hline Lighting power $\left[\mathrm{W} / \mathrm{m}^{2}\right]$ & 4 & 6 & 4 & 8 \\
\hline Illuminance target [lux] & 200 & 500 & 500 & 300 \\
\hline Lighting schedule & Figure 7, a3\&a4 & Figure $7, \mathrm{~b} 3 \& \mathrm{~b} 4$ & Figure $7, \mathrm{~d} 3 \& \mathrm{~d} 4$ & Figure $7, \mathrm{c} 3 \& \mathrm{c} 4$ \\
\hline Windows to wall ratio (\%, S-N-E-W) & $50-40-40-40$ & $60-40-40-40$ & $60-40-40-40$ & $60-50-50-50$ \\
\hline
\end{tabular}

social and company policies in Sweden champion flexible and remote working culture as part of a balanced and gender-equal lifestyle. As a result, we assume that the energy demand due to telecommuting and distant working has been already considered in the existing Swedish building regulations and statistics.

The heating set point in all the residential buildings is assumed at 21 ${ }^{\circ} \mathrm{C}[21]$ and the heating is always "on" for the entire heating season, which lasts from October to April in Sweden. All the buildings are considered to be connected with the district heating network, where the heating coefficient of performance (COP) equals to 1.0 [21]. The mechanical ventilation is implemented and it is set at $0.351 / \mathrm{sm}^{2}$ [21], thus
$0.00035 \mathrm{~m}^{3} / \mathrm{sm}^{2}$. In addition, an infiltration of 0.05 air change per hour (ACH) is considered as a typical new building in Sweden.

The window sizes and their orientations can determine how much solar radiation can come into the building, and hence how much free gain that is possible to use during the winter season. On the other hand, during the summer season, a high share of solar radiation coming into the building could cause overheating problem and increase the cooling demand. Francesco Goia [26] studied three different cities in different locations, in which Oslo $\left(59^{\circ} 57^{\prime}\right)$ is northernmost city and its results can be useful for Borlänge since they are about at the same latitude. The optimal window-to-wall ratios (WWR) in buildings in different locations 
are considered carefully by referring the design in Oslo $\left(59^{\circ} 57^{\prime}\right.$ - same latitude of Borlänge). Different orientations have different optimal WWR. In particular, the optimal range for the south is $0.5-0.6$, while for the other orientations is always $0.37-0.43$ [26]. However, the recommended ranges are meant for office buildings and not for residential. We thus set the lower part of the range for the south direction, with a WWR of 0.5 towards south and 0.4 towards the other directions. Both SVEBY and BFS 2016:12 BEN1 suggests DHW load at $25 / \eta_{\text {syst }}\left[\mathrm{kWh} / \mathrm{m}^{2}\right]$ for new apartments $[21,23]$, with $\eta_{\text {syst }}$ the efficiency of the system (1.0 in case of district heating). As a result, DHW load is assumed at $25 \mathrm{kWh}$ / $\mathrm{m}^{2}$.

\subsubsection{Office buildings}

The office buildings have an occupancy density of 0.05 person $/ \mathrm{m}^{2}$, which means $20 \mathrm{~m}^{2}$ per person [21]. The equipment power density is higher than the residential one and it is set at $10 \mathrm{~W} / \mathrm{m}^{2}$, while the lighting power density is set at $6 \mathrm{~W} / \mathrm{m}^{2}$. The heating set point is at $21^{\circ} \mathrm{C}$ and the heating COP is still considered 1.0 with the district heating network. These buildings have a cooling system with set point at $26^{\circ} \mathrm{C}$ and COP equals to 3.0. The mechanical ventilation is present and considers $1.31 / \mathrm{sm}^{2}$ [21], thus $0.0013 \mathrm{~m}^{3} / \mathrm{sm}^{2}$. In addition, an infiltration of $0.05 \mathrm{ACH}$ is considered. The WWR is equal to be 0.6 towards south and 0.4 to all the other directions in order to have the maximum advantage from the solar radiation all over the year [26]. DHW load is assumed at 2 $\mathrm{kWh} / \mathrm{m}^{2}$, according to the building regulation (BBR 26 [21]).

\subsubsection{Retail shops}

The occupancy density is higher in the shops at about $0.3 \mathrm{p} / \mathrm{m}^{2}$, around $3 \mathrm{~m}^{2}$ per person. The activity power density is thought to be 15 $\mathrm{W} / \mathrm{m}^{2}$, precisely $7 \mathrm{~W} / \mathrm{m}^{2}$ for the equipment and $8 \mathrm{~W} / \mathrm{m}^{2}$ for the lighting. The heating set point for retail shops is at $21{ }^{\circ} \mathrm{C}$, the COP is considered to be 1.0 and the cooling system is present. The cooling set point is at $26^{\circ} \mathrm{C}$ with a COP of 3.0. In addition, there is a mechanical ventilation system with minimum fresh air per area equal to $0.0023 \mathrm{~m}^{3} / \mathrm{sm}^{2}$ (by considering the minimum of 7 1/s per person [21]). In addition, an infiltration of $0.05 \mathrm{ACH}$ is considered. WWR is set at 0.6 towards south and 0.5 to all the other directions by considering the recommendation of reference [26] and practical showcase purpose. DHW load is assumed at $2 \mathrm{kWh} /$ $\mathrm{m}^{2}$, according to the building regulation (BBR $26[21]$ ).

\subsubsection{School}

BBR regulation suggests the occupancy density of school at 0.067 person $/ \mathrm{m}^{2}[21]$. Therefore, the activity power density is set at $12 \mathrm{~W} / \mathrm{m}^{2}$ with $4 \mathrm{~W} / \mathrm{m}^{2}$ for the lighting power and $8 \mathrm{~W} / \mathrm{m}^{2}$ for the equipment. In the school, the heating set point is set at $22^{\circ} \mathrm{C}$, and the COP is set at 1.0. The cooling system has a set point of $26^{\circ} \mathrm{C}$ with a COP of 3.0. There is a mechanical ventilation system with minimum fresh air per area equal to $0.0025 \mathrm{~m}^{3} / \mathrm{sm}^{2}\left(2.5 \mathrm{l} / \mathrm{sm}^{2}\right)$ [21]. In addition, an infiltration of $0.05 \mathrm{ACH}$ is considered. The size and orientation of the windows in a school are considered to be similar to an office because of the similarity on daylight needed in the large spaces. Thus, the same values of WWR ratio are used: 0.6 towards south and 0.4 to all the other directions. DHW load is assumed at $25 \mathrm{kWh} / \mathrm{m}^{2}$, according to the building regulation (BBR 26 [21])..

\subsubsection{Schedules}

In this study, the schedules are defined according with BBR 26 regulation [21] or practical assumptions in Table 1. For instance, in a residential building of the base case, the lights are considered to be on during two times in the weekdays: one in the morning around 7/8 am and then during the evening. During the weekends, part of the lights are also considered to be on during the day. There are mainly two peaks for equipment during the weekdays and a larger use in the weekends. Part of equipment, such as fridge, are considered to be always on. The heating is always on in order to keep the set point temperature and protect the buildings from moisture damage during the heating season, which starts the first of October and ends the thirtieth of April. From May to September, the heating is considered to be totally off. The rest schedules for offices, retail shops and the school are similar to each other. Retail shops are considered to be opened over the year in the base case, while offices have one month vacation in August and school has a lower occupancy density in July. The cooling season in all of these facilities lasts for three month and a half, which starts in middle May and finishes at the end of August. The rest schedules for other scenarios can be referred to Table 1 .

Fig. 7 illustrates an example of the schedules setup in confinement level 2 for occupancy, lighting, equipment, and cooling in each building type: (a) residential building, (b) office, (c) retail shop, and (d) school. The heating is assumed to be turned on all the time $(24 \mathrm{~h})$ during the heating season, from first of October and ends the thirtieth of April. There is no heating from May to September. DHW is set up at the same load across seasons on an annual base. There is no cooling system in residential buildings. On confinement level 2 , it is assumed that the unoccupied hours in residential building are $5 \mathrm{~h}$ in total each day. For instance, as indicated in Fig. 7 (a), each $2.5 \mathrm{~h}$ in the morning and afternoon are assumed for outdoor activities during weekdays, while outdoor hours appear mostly in the afternoon during weekends. These changes in occupancy then influence the setups in school and office buildings. There will be 5 occupied hours in school, and $4.5 \mathrm{~h}$ in office building respectively, as shown in Fig. 7 (b) and (d). The schedule of retail shops, as shown in Fig. 7 (c), is $4 \mathrm{~h}$ longer than that in base case, which are the same for both weekdays and weekends. All the associated lighting and equipment, as well as cooling schedule, are then changed according to the occupancy schedules in each building type, based on the default setup in the base case.

\section{Results and discussion}

\subsection{Detailed simulation results of base case (level 1)}

Fig. 8 visualized the total energy demands of all the studied buildings in one year, which varying from $13,372 \mathrm{kWh} /$ year to $483,056 \mathrm{kWh} /$ year. Both Fig. 9 and Fig. 10 further break down the all energy consumed categories according to each archetype. In general, there are three dominant energy consumptions in the studied district, where heating, equipment, and lighting account for $40 \%, 30 \%$ and $27 \%$ respectively. Once looking into each archetype, the principal archetype is the residential building, which need $60 \%$ of electricity in lighting category and $94 \%$ in heating category, due to its greatest floor area percentage in the district (except for the cooling demand). From the aspect of areaweighted average energy demand, the total energy demand of the district is simulated with the results of about $80.0 \mathrm{kWh} / \mathrm{m}^{2} /$ year in average. More details can be found in Table 5 . It can be divided into the different archetypes as followings: $64.1 \mathrm{kWh} / \mathrm{m}^{2} /$ year for the school; $92.2 \mathrm{kWh} / \mathrm{m}^{2} /$ year for the retail shops; $72.1 \mathrm{kWh} / \mathrm{m}^{2} /$ year for the offices; $80.4 \mathrm{kWh} / \mathrm{m}^{2} /$ year for the residential buildings. Among these, retail shops have the highest energy demand due to the high needs in lighting and the equipment operation. Nevertheless, the retail shops have a relatively low heating need $\left(2.4 \mathrm{kWh} / \mathrm{m}^{2}\right)$. Higher occupancy density, electrical energy demands and higher WWR together contribute to useful heat gains in reducing the heating load accordingly. On the other hand, these heat gains are not so useful during the summer time. Therefore, the retail shops need most cooling demand in order to avoid overheating issues. Residential buildings ranks the second since the heating demand and the DHW loads are high. Offices and school have nearly the same energy demands, due to the similarity of the input parameters. Offices have a slightly greater consumption in lighting and equipment, hence in cooling consumption, but the heating need is a bit lower.

In this study, apart from the total energy demand, we also define the delivered electricity demand and the system energy demand. The delivered electricity demand is the sum of lighting and equipment power 
1) Residential Occupancy Weekdays

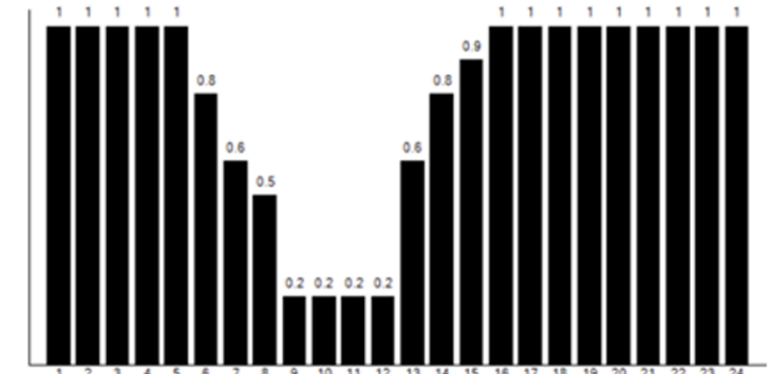

3) ResidentialLighting Weekdays

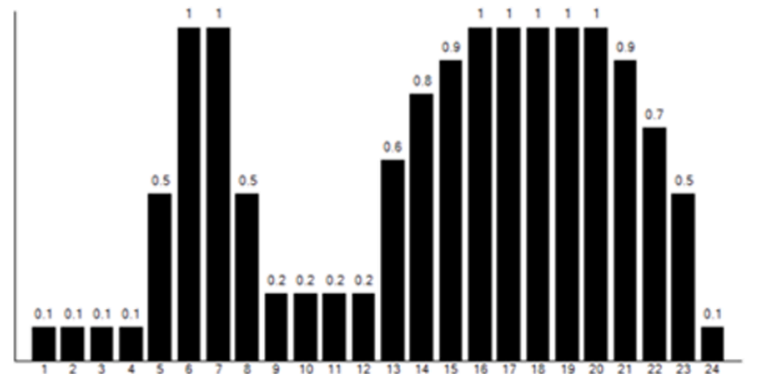

5) Residential Equipment Weekdays

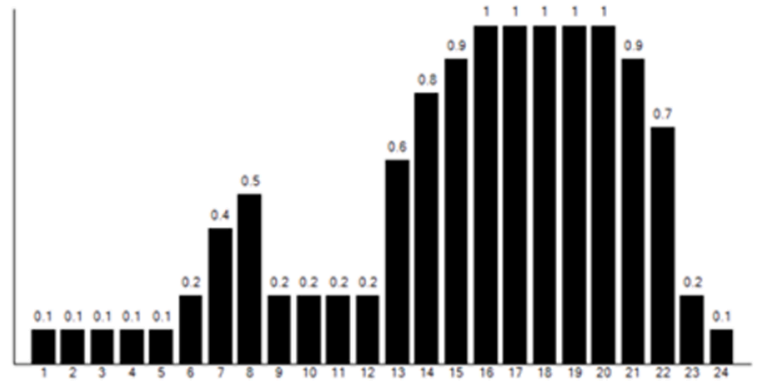

2) Residential Occupancy Weekends \& Holidays

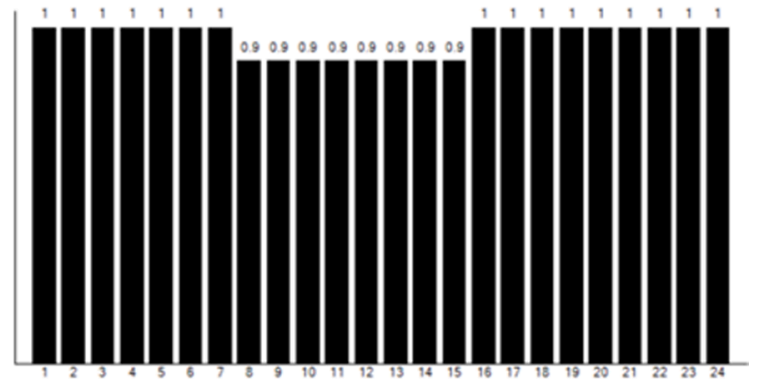

4) Residential Lighting Weekends \& Holidays

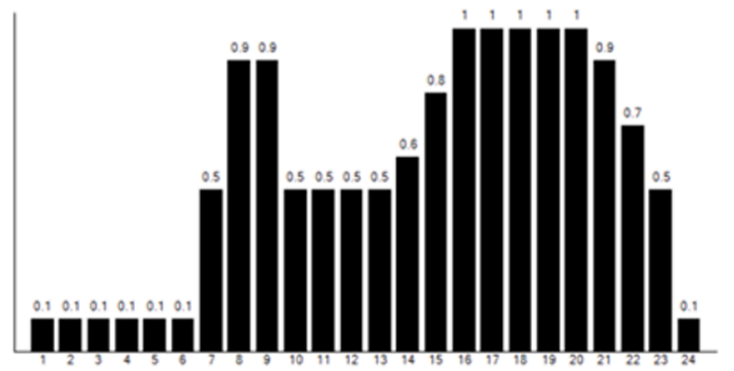

6) Residential Equipment Weekends \& Holidays

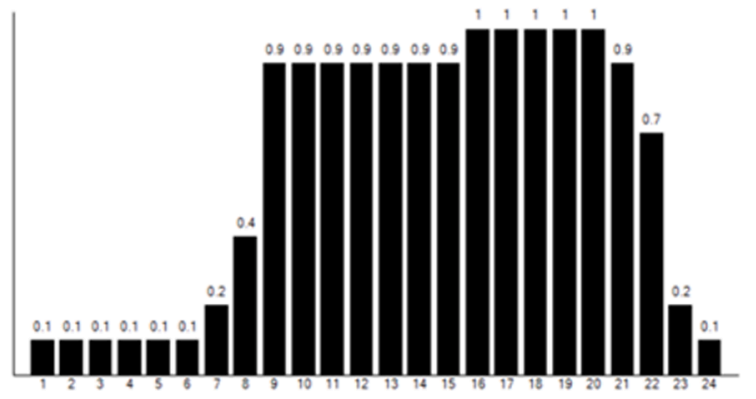

(a)

Fig. 7. Example of schedules setup in confinement level 2 for occupancy, lighting, equipment, and cooling for each building type: (a) residential building, (b) office, (c) retail shop, and (d) school.

loads, while the system energy demand is the sum of other service system energy needs, such as heating, cooling and DHW.

Fig. 11 displays these two energy demands varying with floor areas. It is observed that the delivered electricity demand increases nearly linearly with the increasing of the floor area, since the key parameters are set according to the floor areas. In contrast, it is not obvious to find a similar trend in the system energy demand, which largely follows the trend of normalized heating demand. There may be two reasons for this: firstly, the DHW demands are set according to individual archetype instead of being dependent on the floor area; secondly, the cooling is not needed in all residential buildings, which account for the greatest total floor area in the district.

Fig. 12 presents explicit monthly variations of the studied energy demands in accordance to each archetype. The delivered electricity demand generally has a relatively smooth annual variation. On the contrary, the system energy possess a distinct seasonal deviation, where it is significantly high during the heating season (starts the first of October and ends the thirtieth of April), but much low from April to September. It is found that the district achieves the peak system energy demand in January when external air temperature is the lowest, dominating by heating demand; it requires least system energy demand in September, when heating and cooling are not needed so much during the transition season.

\subsection{Uncertainty analysis}

Because this whole study is fully investigated through model setup and simulation, all the results are highly dependent on the assumptions and inputs. Therefore, it is necessary to have an uncertainty analysis about the input parameters based on the simulated results. It is conducted using the base case for the purpose of uncertainty analysis. In general, there are four main types of inputs into the model, which are occupancy profile, DHW load, electrical equipment power density and lighting power density.

\subsubsection{Occupancy profile input}

According to Table 1 and Table 4, the occupancy density (person/ $\mathrm{m}^{2}$ ) is set with $0.04,0.05,0.067$ and 0.3 for residential buildings, office buildings, school and retail shops respectively, while the occupancy duration (hours/day/person) is set with 14, 9, 10, 10 and 10 respectively. The occupancy density inputs follow the lower design thresholds from Swedish standards of BBR 26 [21] and BFS 2016:12 BEN [23]. At the same time, the occupancy durations are derived from reports in SVEBY for residential building [17], school [18] and commercial building [19], as well as BBR 26 [21] and BFS 2016:12 BEN [23], especially supporting by several individual studies from Statistics Sweden. Among these, SVEBY stands for "Standardize and verify energy 
1) Office Occupancy Weekdays

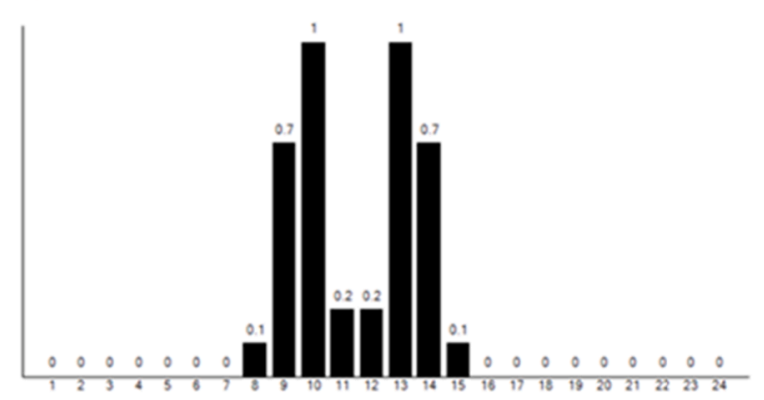

3) Office Lighting Weekdays

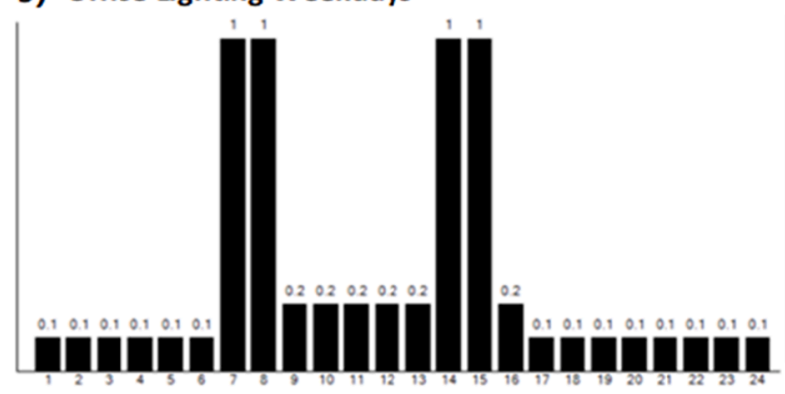

5) Office Equipment Weekdays

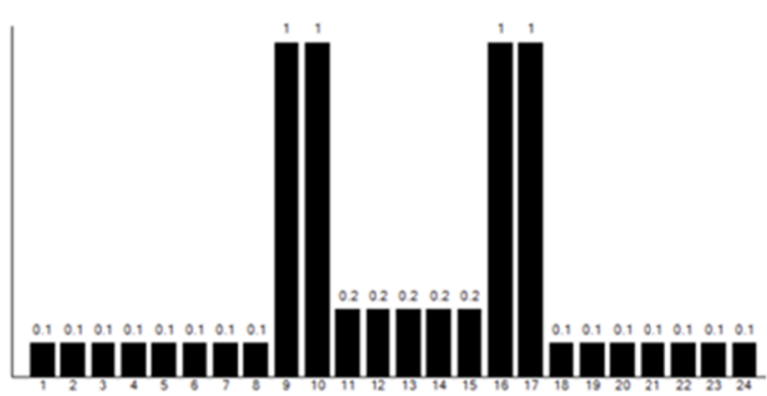

7) Office Cooling Weekdays

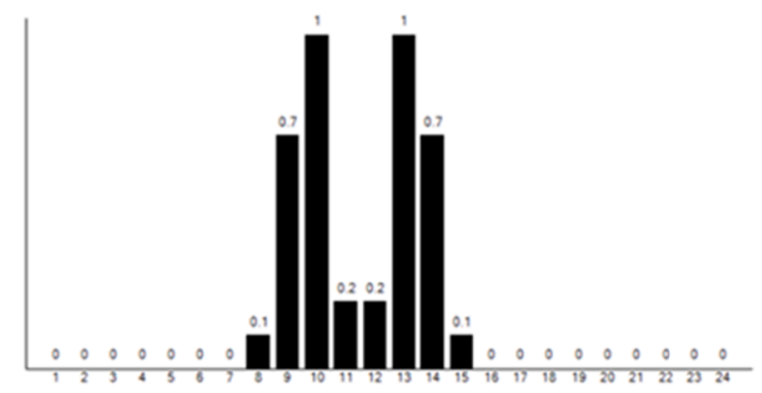

2) Office Occupancy Weekends \& Holidays

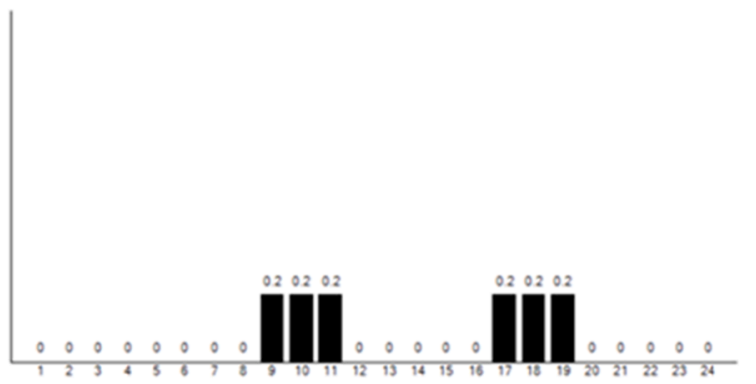

4) Office Lighting Weekends \& Holidays

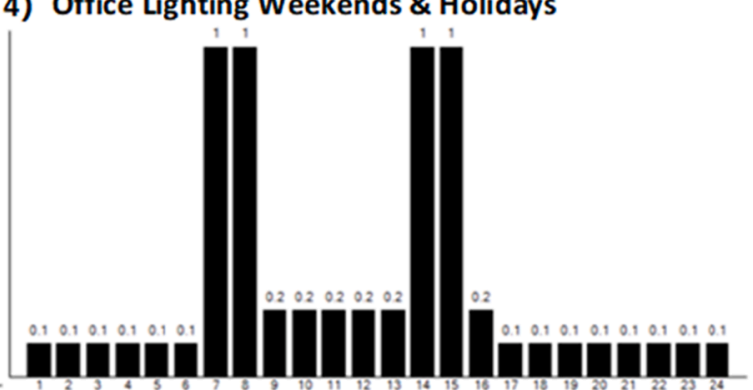

6) Office Equipment Weekends \& Holidays

(b)

Fig. 7. (continued).

performance in buildings", which is a development program run by the construction and real estate industry, aiming for definition and verification of buildings' energy performance. In SVEBY's reports, user behaviours is continuously updated over time since 2012 in order to obtain continuity and clarity in verification. Thus, it is important that input data is reasonably set up according to the statistics in SVEBY's manuals [27]. For instance, there were two main concluded average occupancy duration hours for residential buildings. The first average occupancy hours is $15.5 \mathrm{~h}$ /day person that is concluded from 179 households investigations from different types of places and parts of Sweden, while the another average value is popularly accepted with the average value of $14 \mathrm{~h} /$ day/person. In this study, we take the latter value as the input in the model.

\subsubsection{DHW information input}

Regarding the DHW load, the input ( $\mathrm{kWh} / \mathrm{m}^{2}$ per year) is set with 25 , 2, 2, 2 for residential buildings (taking majority type of multifamily building), office buildings, school and retail shops respectively, which are in accordance to the design suggestions from SVEBY for residential building [17], school [18] and commercial building [19], as well as study [28]. Some of these values are also backed up by statistic studies in Sweden. The DHW load of residential buildings comes from a study of 1500 apartments in Stockholm between 1997 and 2003 [29]. The load of office buildings is derived from the average value from the statistics of 
1) Retail Occupancy Weekdays

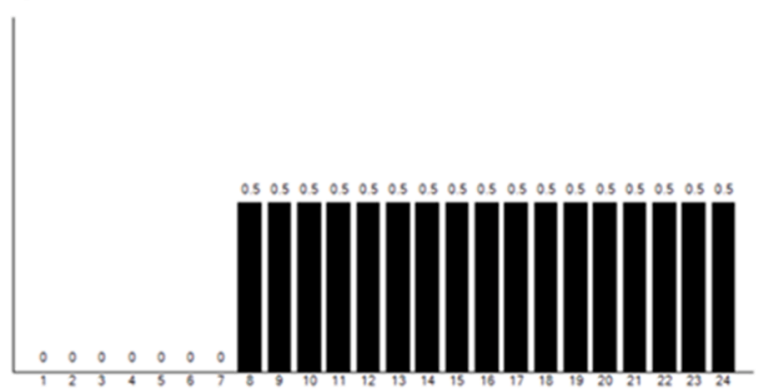

3) Retail Lighting Weekdays

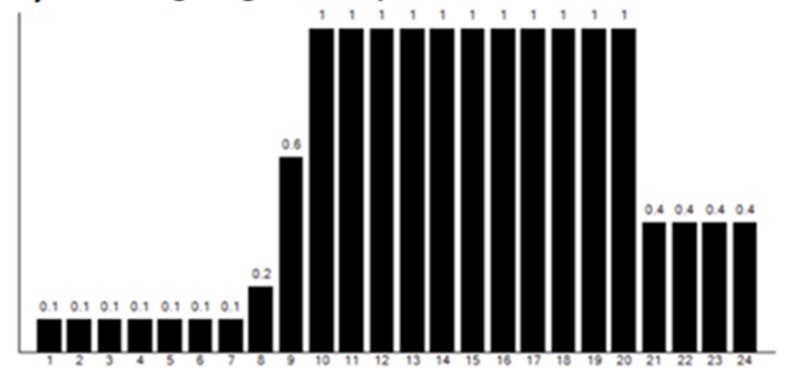

5) Retail Equipment Weekdays

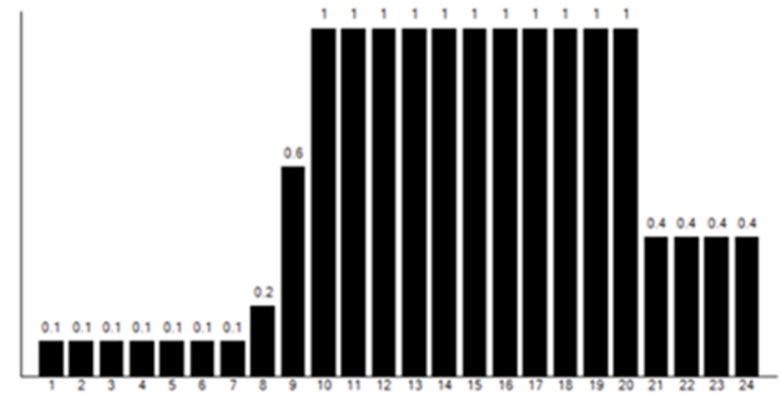

7) Retail Cooling Weekdays

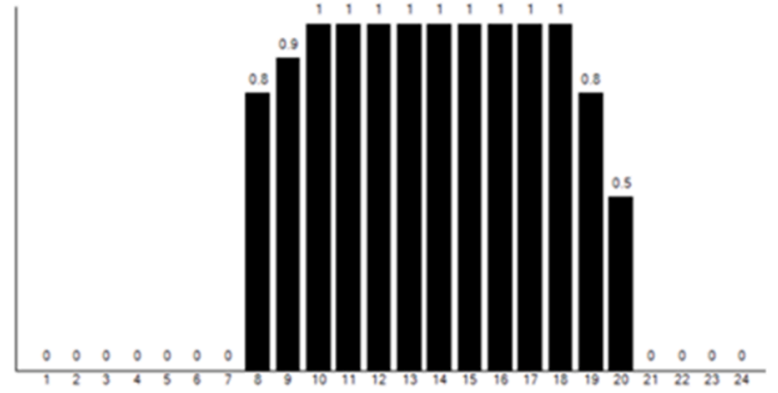

\section{2) Retail Occupancy Weekends \& Holidays}

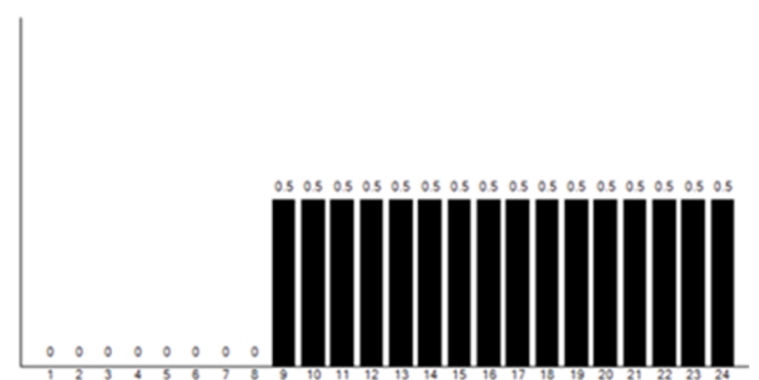

4) Retail Lighting Weekends \& Holidays

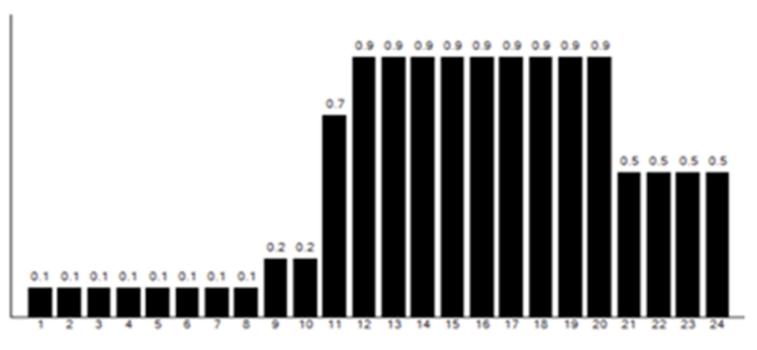

6) Retail Equipment Weekends \& Holidays

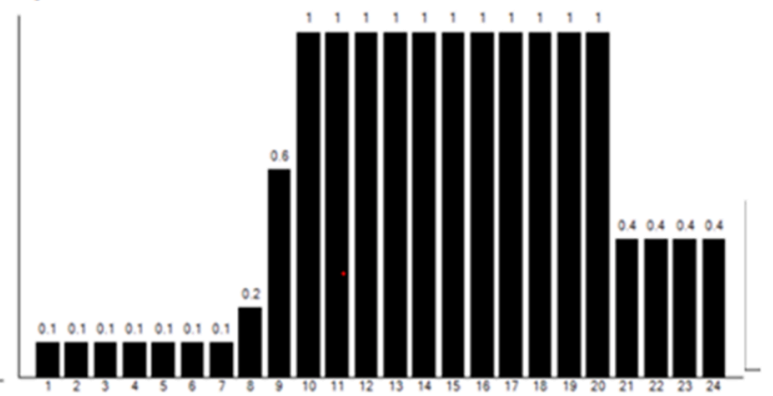

8) Retail Cooling Weekends \& Holidaysekdays

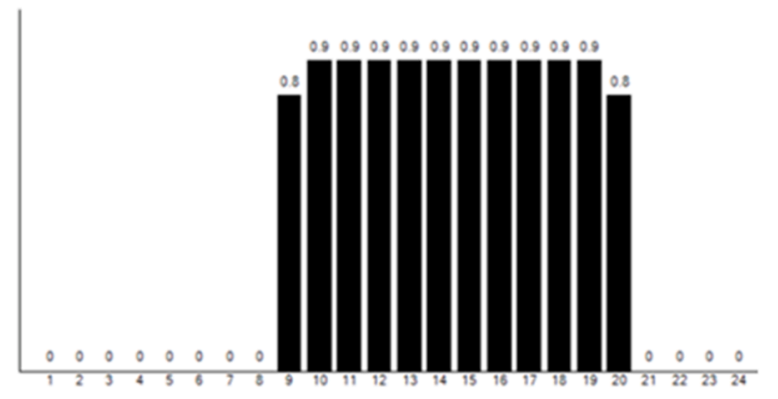

(c)

Fig. 7. (continued).

several office properties [30]. The DHW load of school is selected for either the primary school or the high school in Sweden [23].

\subsubsection{Input of lighting and equipment}

Other than the inputs of occupancy and annual DHW load, the electrical inputs of residential buildings are more sensitive to the final outputs, for the reason that greater magnitude of amount and the following lock down modes investigation. According to the power density of lighting and equipment in Table 4, two input categories (parameter range) have been defined for lighting and equipment power density respectively, using the value uniformly discrete within the suggested parameter range in the references of SVEBY for residential building [17], and statistics in previous studies [28,30] and surveys
[31]. The proposed sensitivity analyses cover all the archetypes with total 16 varied cases, for the purpose in exploring the potential impacts from these two critical inputs on the entire district energy performance in a year. In each case, only one value from the potential input category is tested on one building type, while other parameters keep their given values as same as that in the base case.

Fig. 13 and Fig. 14 demonstrate the sensitive impacts of the two input categories on 'normalized delivered electricity demand' and 'normalized system energy demand' for this district in a year. In each diagrams, there are 5 dots in each archetype, including the default value existed in the base case and corresponding 4 parameters that vary with $0.5 \mathrm{~W} / \mathrm{m}^{2}$ each time and for comparison. For instance, the default equipment power density is $4 \mathrm{~W} / \mathrm{m}^{2}$ in residential buildings, so that the tested equipment 
1) School Occupancy Weekdays

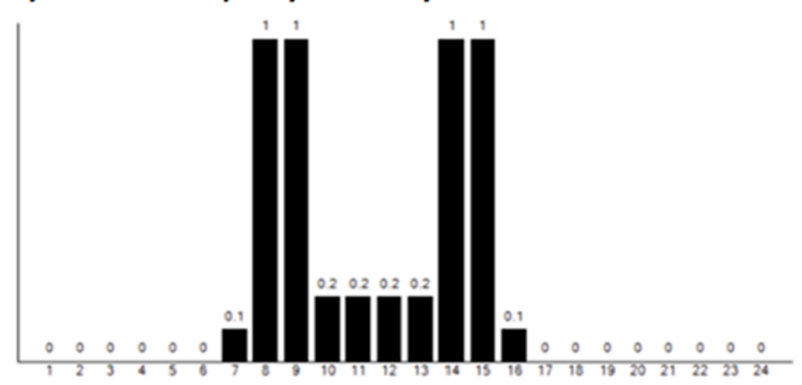

3) School Lighting Weekdays

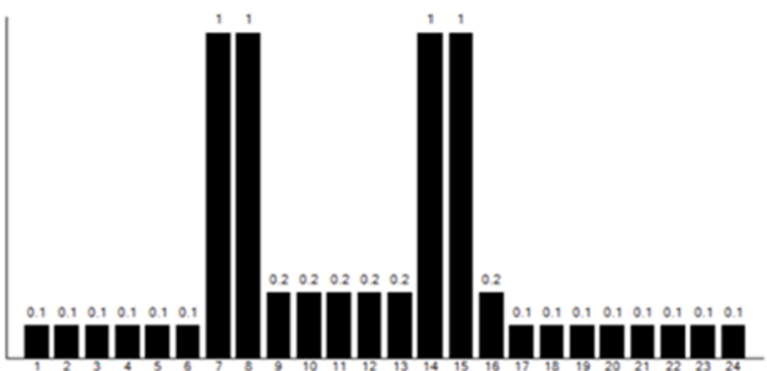

5) School Equipment Weekdays

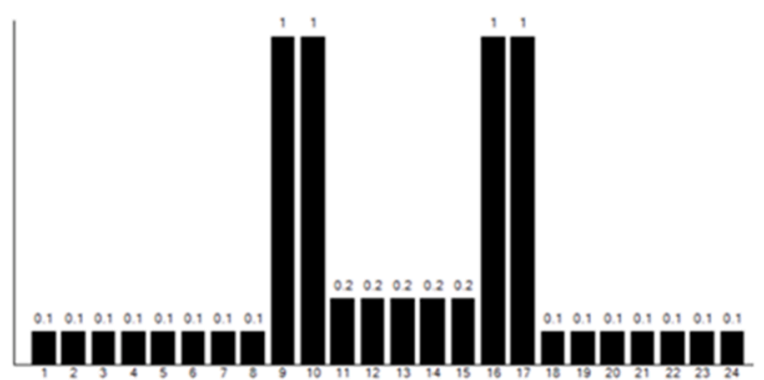

7) School Cooling Weekdays

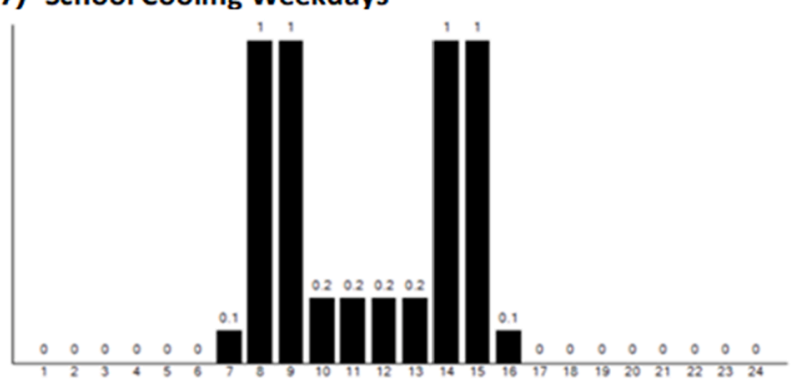

\section{2) School Occupancy Weekends \& Holidays}

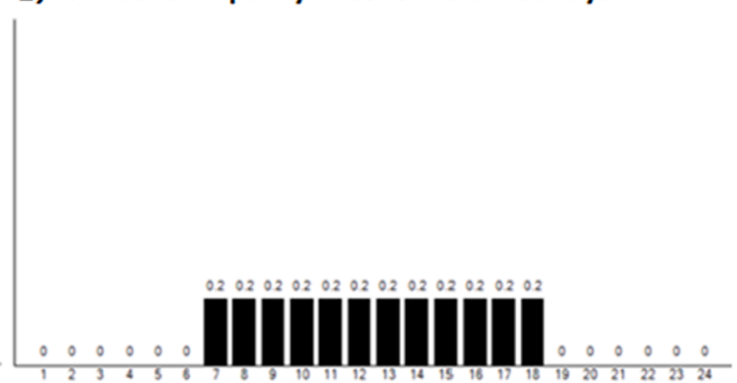

4) School Lighting Weekends \& Holidays

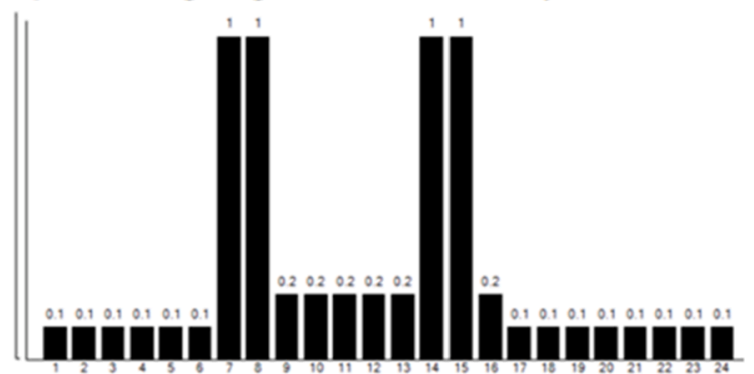

6) School Equipment Weekends \& Holidays

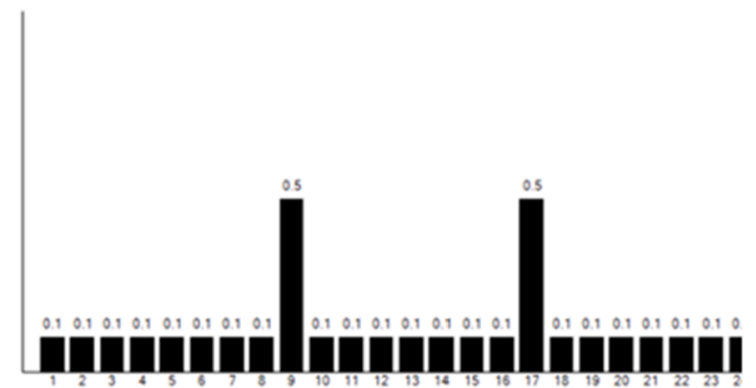

(d)

Fig. 7. (continued).

power density values are set at $3 \mathrm{~W} / \mathrm{m}^{2}, 3.5 \mathrm{~W} / \mathrm{m}^{2}, 4.5 \mathrm{~W} / \mathrm{m}^{2}, 5 \mathrm{~W} / \mathrm{m}^{2}$ respectively in the same residential buildings. It is clear that all the tested parameters have reasonable sensitivity performance by comparing to the base case. In terms of the normalized delivered electricity load, the deviations change in range of $-2.8 \%$ to $2.5 \%$ from the angle of equipment power density variation, and in the range of $-2.6 \%$ to $2.5 \%$ from the aspect of lighting power density variation. In terms of normalized system energy load, the maximum deviations are even less, which are in the range of $-0.7 \%$ and $0.6 \%$ from the aspect of equipment power density variation, and in the range of $-0.4 \%$ and $0.6 \%$ from the view of lighting power density variation. The majority of the discrepancy percentages appear around $\pm 0.1 \%$. All the noteworthy deviations are only discovered in the residential buildings, because residential buildings account for the largest floor area in the whole district, leading this archetype become the most varying one. But the overall impact on the residential building is limited with the acceptable discrepancy ratios (i.e. $\pm 2.8 \%$ ) in both varying cases.

\subsubsection{Comparison to the building standards}

In this section, the weighted average system energy demand from the base case is compared with the requirement at different local standards, including the Swedish Housing Agency's building rule [21], Passive house standard in Sweden (FEBY18) [32], and Swedish green building standard (Miljöbyggnad) [33]. Table 6 presents the comparison results. It is found that the weighted average system energy demand is simulated at about $47.6 \mathrm{kWh} / \mathrm{m} 2 /$ year, which is much lower the basic requirement 


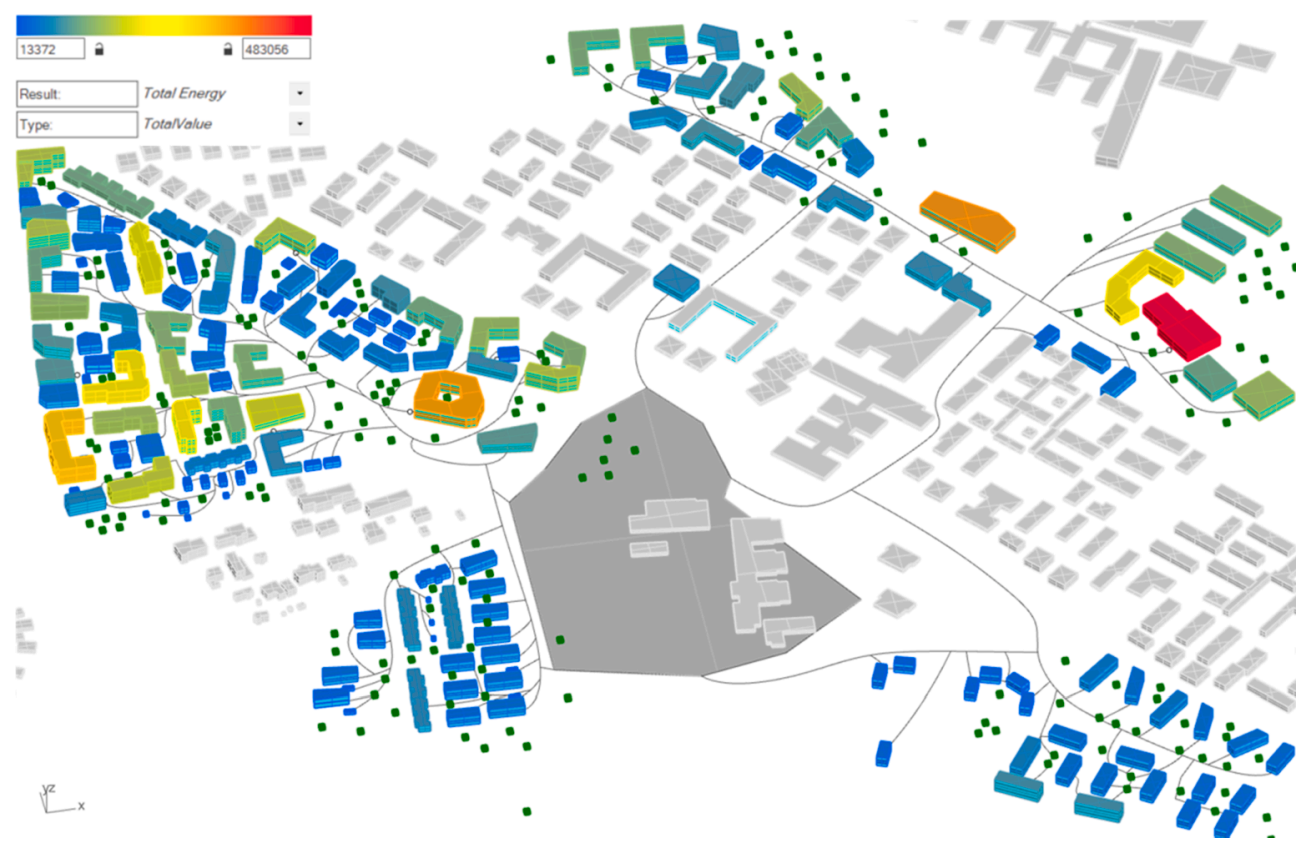

Fig. 8. Visualization of total energy demands in the residential district in one year.

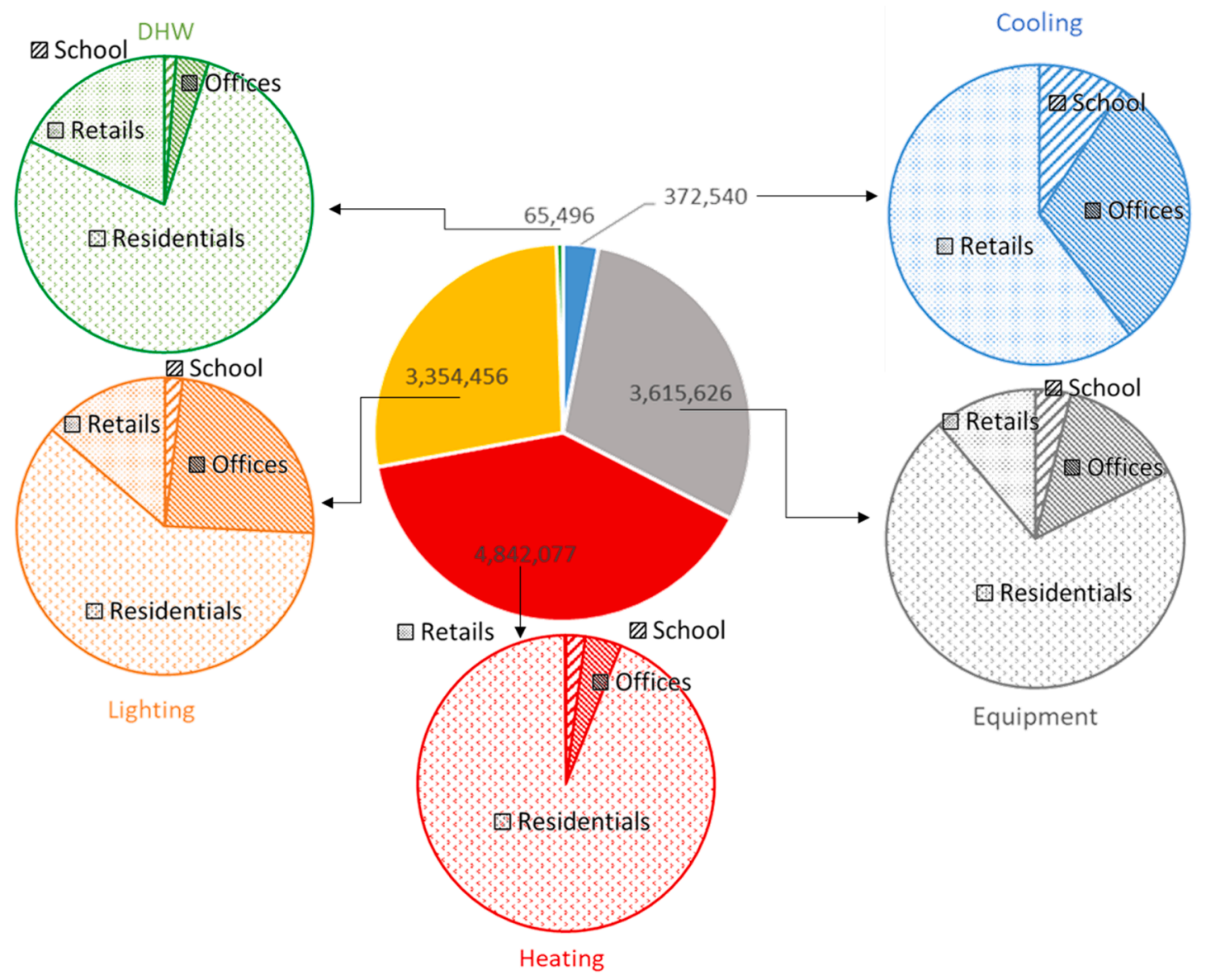

Fig. 9. Breakdown pie charts of all energy consumed items for each archetype in the district [kWh/annual]

in building regulation (BBR26), and it meets the gold level of passive house standard. But it is a bit higher that the requirement of gold level in green building standard. As a result, the simulation result is reasonable by comparing to local standards.

\subsection{Simulation results of different confinement levels}

Table 7 reports the summary of the simulation results in different confinement levels. In the level 2, confinement measures are considered 


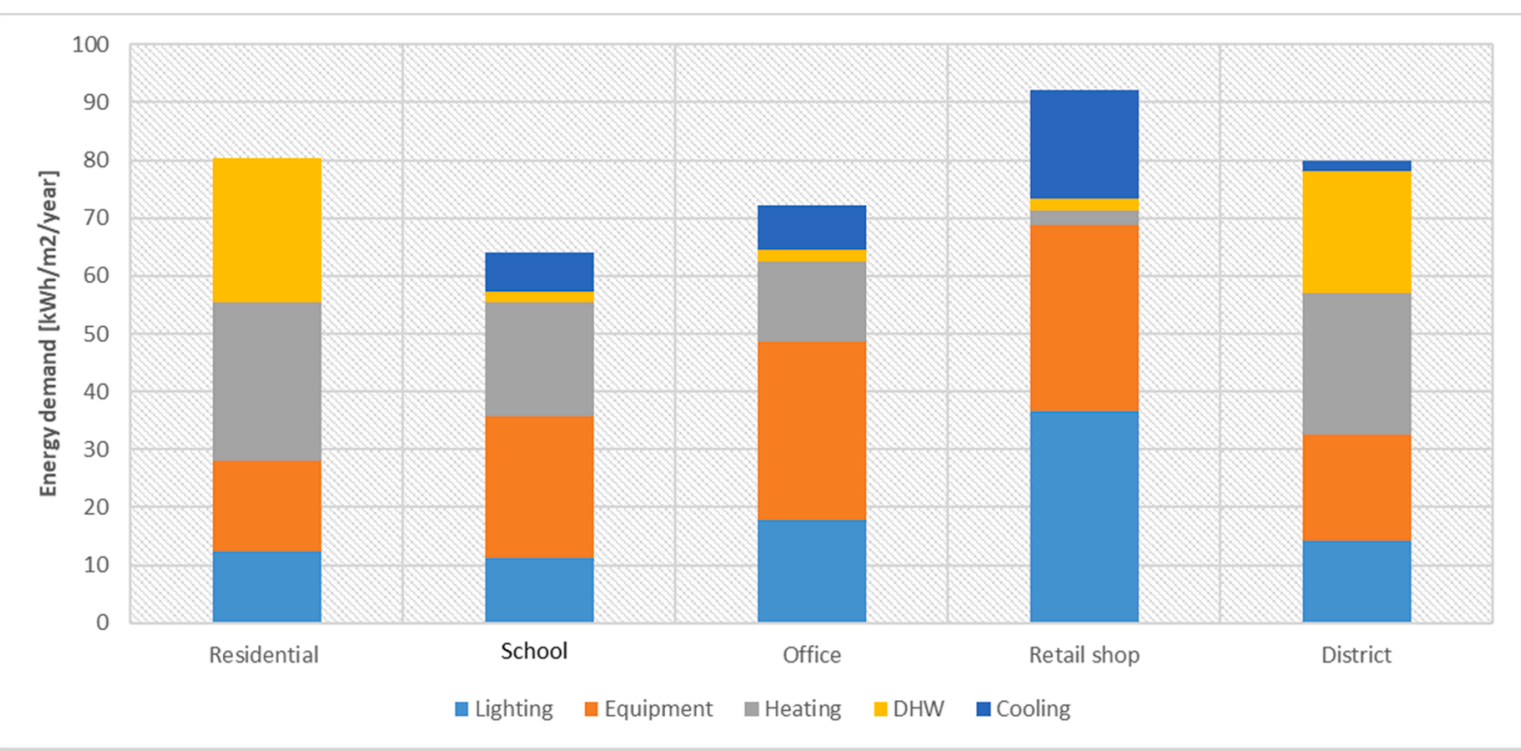

Fig. 10. Share of normalized individual energy demand in each archetype.

Table 5

Energy demands for each archetype at base case in one year duration.

\begin{tabular}{|c|c|c|c|c|c|c|c|c|}
\hline \multirow[t]{2}{*}{ Archetype } & $\begin{array}{l}\text { Lighting } \\
{\left[\mathrm{kWh} / \mathrm{m}^{2}\right]}\end{array}$ & $\begin{array}{l}\text { Equipment } \\
{\left[\mathrm{kWh} / \mathrm{m}^{2}\right]}\end{array}$ & $\begin{array}{l}\text { DHW } \\
{\left[\mathrm{kWh} / \mathrm{m}^{2}\right]}\end{array}$ & $\begin{array}{l}\text { Heating } \\
{\left[\mathrm{kWh} / \mathrm{m}^{2}\right]}\end{array}$ & $\begin{array}{l}\text { Cooling } \\
{\left[\mathrm{kWh} / \mathrm{m}^{2}\right]}\end{array}$ & $\begin{array}{l}\text { Delivered } \\
\text { electricity [kWh/ } \\
\left.\mathrm{m}^{2}\right]\end{array}$ & $\begin{array}{l}\text { System energy } \\
{\left[\mathrm{kWh} / \mathrm{m}^{2}\right]}\end{array}$ & $\begin{array}{l}\text { TOTAL energy demand } \\
{\left[\mathrm{kWh} / \mathrm{m}^{2}\right]}\end{array}$ \\
\hline & $0 ; 1$ & $0 ; 2$ & $0 ; 3$ & $0 ; 4$ & $0 ; 5$ & $0 ; 1+0 ; 2$ & $0 ; 3+0 ; 4+0 ; 5$ & $0_{; 1}+0_{; 2}+0 ; 3+0 ; 4+0 ; 5$ \\
\hline \multicolumn{9}{|c|}{ Base case with no COVID-19 influence (Area weighted average: average values are calculated based on the respective area percentage of each archetype) } \\
\hline $\begin{array}{l}\text { Residential }(82.7 \% \\
\text { of total area) }\end{array}$ & 12.3 & 15.6 & 25.0 & 27.4 & 0.0 & 28.0 & 52.4 & 80.4 \\
\hline $\begin{array}{l}\text { School ( } 2.9 \% \text { of } \\
\text { total area) }\end{array}$ & 11.2 & 24.5 & 2.0 & 19.6 & 6.7 & 35.7 & 28.4 & 64.1 \\
\hline $\begin{array}{l}\text { Retail shop ( } 6.3 \% \text { of } \\
\text { total area) }\end{array}$ & 36.7 & 32.1 & 2.0 & 2.4 & 18.9 & 68.9 & 23.3 & 92.2 \\
\hline $\begin{array}{l}\text { Area weighted } \\
\text { average }\end{array}$ & 14.3 & 18.2 & 21.0 & 24.5 & 2.0 & 32.4 & 47.6 & 80.0 \\
\hline
\end{tabular}
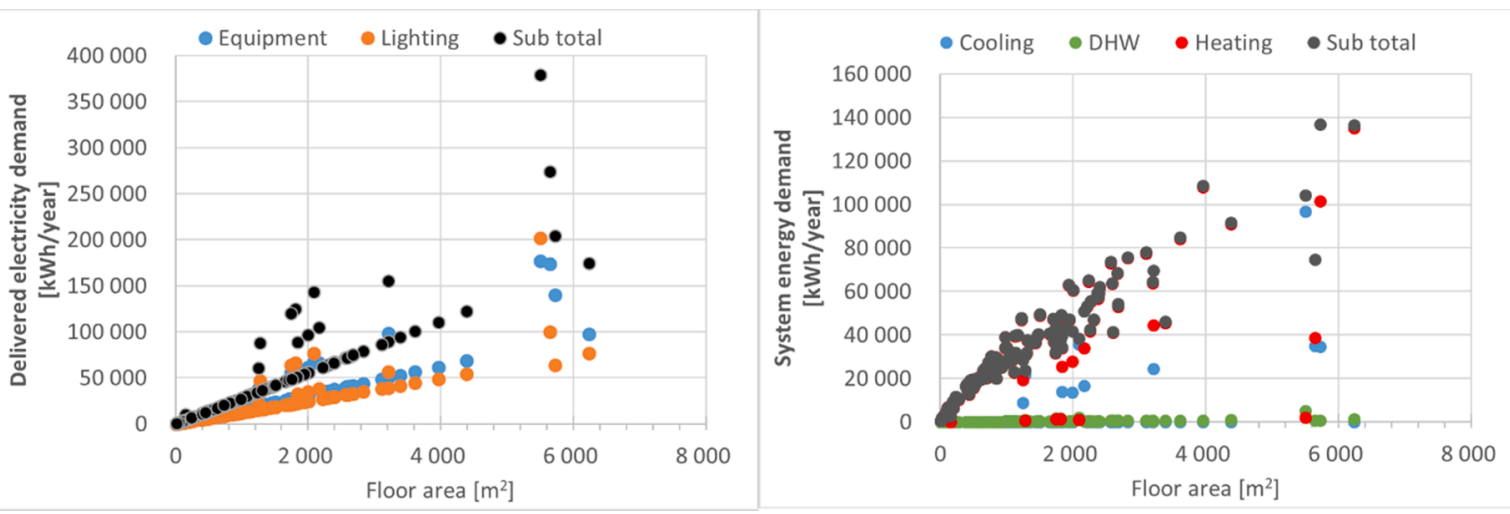

Fig. 11. Scatter plots of energy demand with floor area.

as 'soft' when citizens can go out for work and activities in certain hours. It is observed that the average delivered electricity increase from 32.4 $\mathrm{kWh} / \mathrm{m}^{2} /$ year at level 1 to $38.5 \mathrm{kWh} / \mathrm{m}^{2} /$ year (about $18.7 \%$ increase) at the level 2, contributed mainly by residential buildings and retail shops. This can be explained by the fact that the electricity demand in residential buildings rises when people stay longer time at home, with augmented conventional demand (lighting, cooking and dishwashing) and more equipment demand (online meetings, computation-related workings). The retail shops are run longer for necessary purchase, delivery and pickup of food, medicine and commodity, so a higher electricity demand is found for lighting and equipment. Heating demand varies differently in each archetype, but overall heating is needed less. For instance, heating is less required in residential buildings because of more internal heat gains when people stay longer at home; both school 


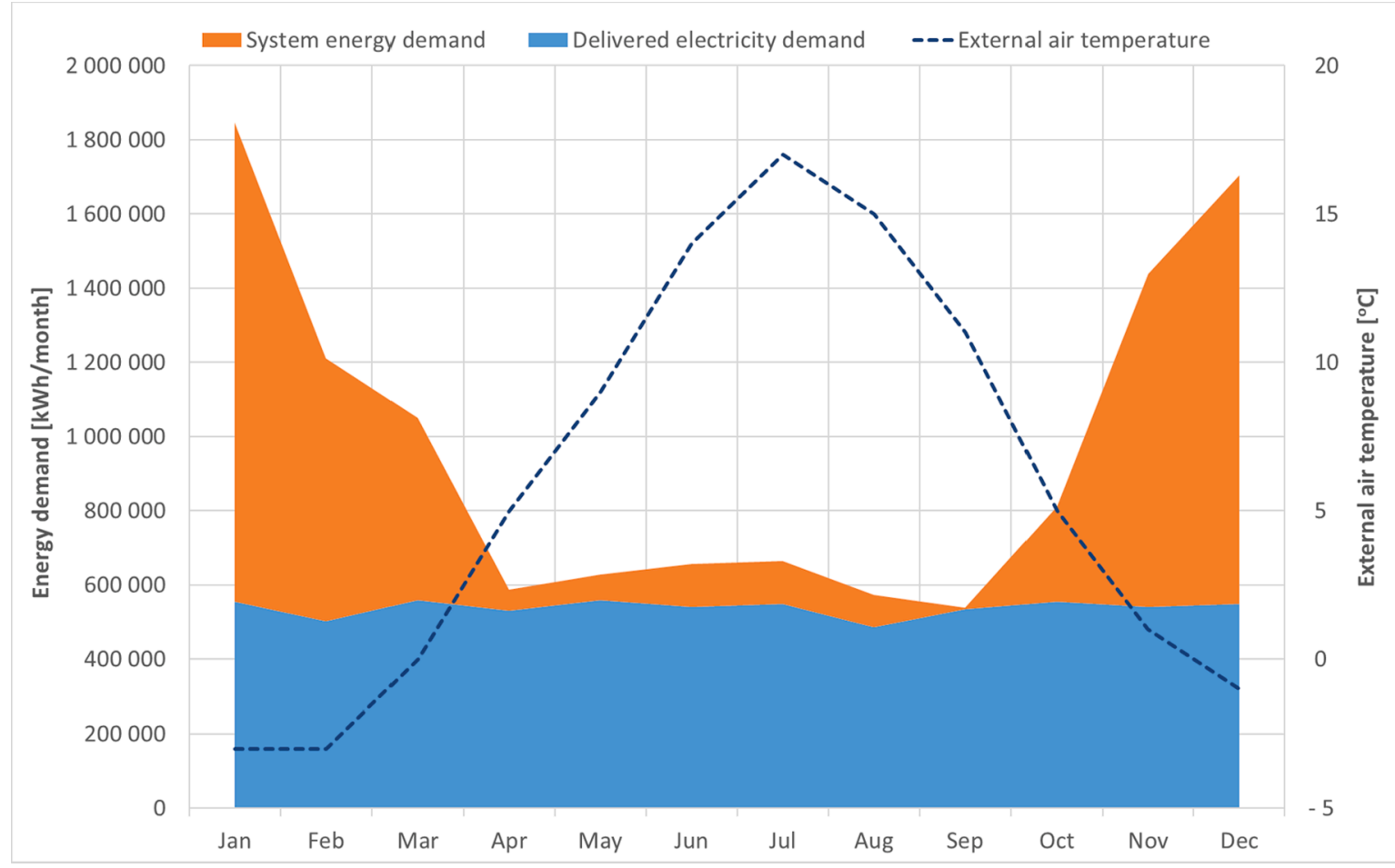

Fig. 12. Variation of energy demands and air temperature with months.
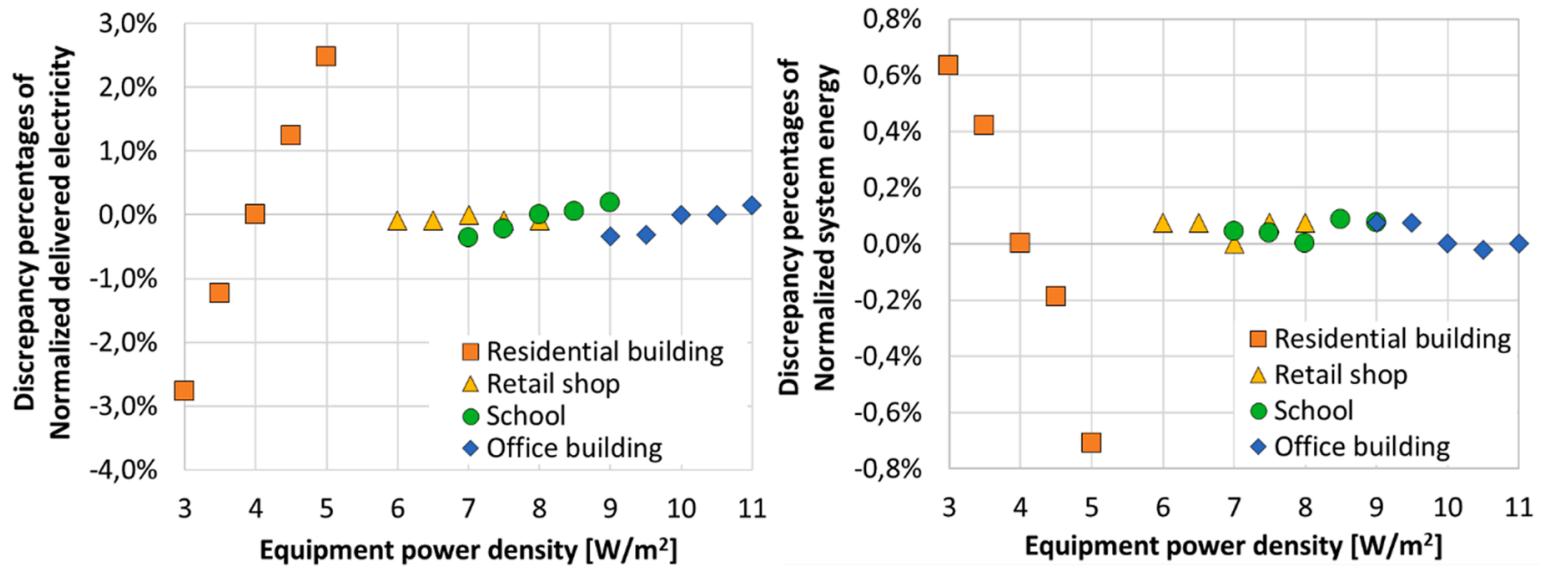

Fig. 13. Sensitive study for impacts of the equipment power density on energy demand.
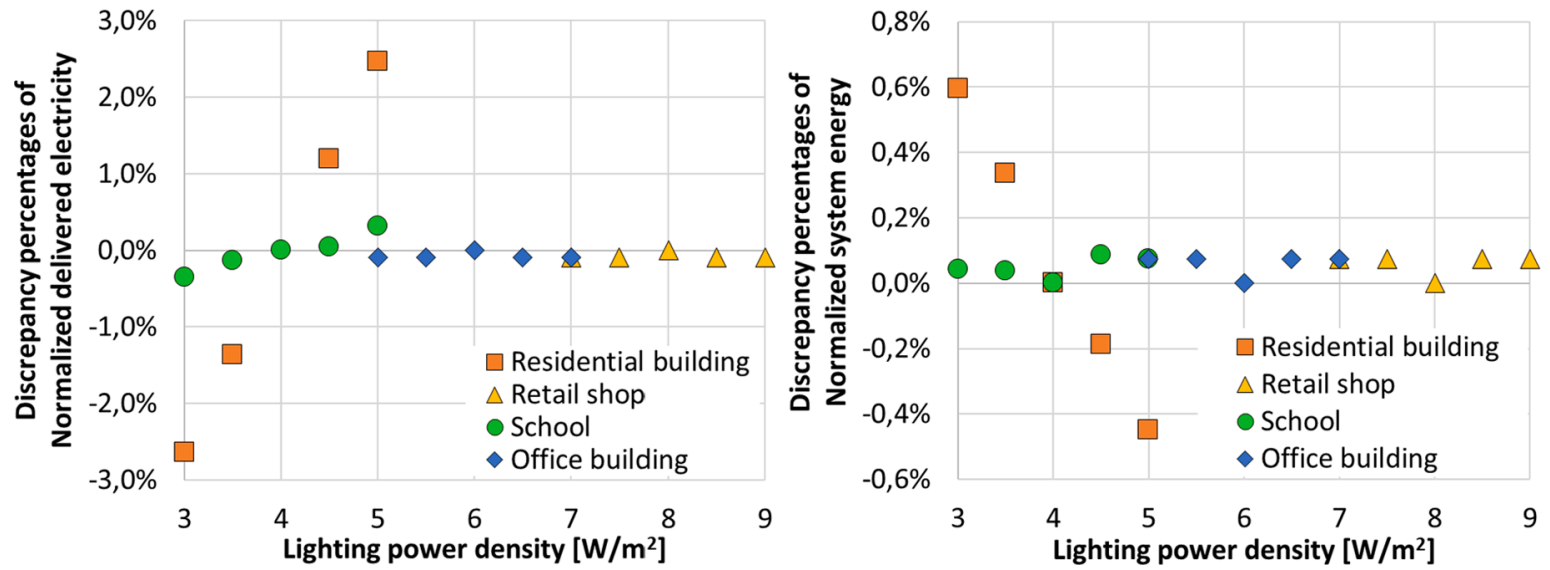

Fig. 14. Sensitive study for impacts of the lighting power density on energy demand. 
Table 6

Comparison of the simulation result to different standards in Sweden.

\begin{tabular}{|c|c|c|c|}
\hline $\begin{array}{l}\text { Area-weighted } \\
\text { average system } \\
\text { energy demand } \\
{\left[\mathrm{kWh} / \mathrm{m}^{2} /\right.} \\
\text { year] }\end{array}$ & $\begin{array}{l}\text { Boverket's } \\
\text { building } \\
\text { regulations (BBR } \\
26)[21] \text { [kWh/ } \\
\mathrm{m}^{2} / \text { year] }\end{array}$ & $\begin{array}{l}\text { Passive house } \\
\text { standard in } \\
\text { Sweden } \\
\text { (FEBY18) [32] } \\
{\left[\mathrm{kWh} / \mathrm{m}^{2} / \text { year] }\right.}\end{array}$ & $\begin{array}{l}\text { Swedish green } \\
\text { building standard } \\
\text { (Miljöbyggnad) [33] } \\
{\left[\mathrm{kWh} / \mathrm{m}^{2} / \text { year] }\right.}\end{array}$ \\
\hline $\begin{array}{l}\text { Base case result } \\
47.6\end{array}$ & $\begin{array}{l}\text { Basic requirement } \\
<=80\end{array}$ & $\begin{array}{l}\text { Gold level } \\
<=52\end{array}$ & $\begin{array}{l}\text { Gold level } \\
<=40\end{array}$ \\
\hline
\end{tabular}

and offices need more heating due to less internal heat gains; in retail shops, heating is needed less when it operates with much lower occupant density and thus with less cold ventilation required. The general cooling demand reduces slightly. Offices and school decrease cooling need as they are open for shorter time with less occupants and less heat gain in summer. While retails shops need a bit more cooling since they are run for longer time, even though they have less internal heat gains due to less occupants. The DHW loads are less than that on level 1 by considering the less occupants in school/offices/shops. The average total system energy demand at this level is about $44.4 \mathrm{kWh} / \mathrm{m}^{2} /$ year, decreasing by $7.1 \%$ comparing to that at level 1 (base case). It is then observed that the increased electricity demand dominates the change in energy demand when DHW, heating and cooling demands are required less.

At the level 3, confinement is even harder than that on level 2. Citizens can still go out for work and activities in fewer hours. The varying trends of energy demands for archetypes, energy categories, and total amount are similar to that on level 2. Comparing to the base case, the average overall electricity demand increases by $17.7 \%$, and the mean total energy demand drops by $10.0 \%$. The increased ranges are slightly smaller than that on level 1 . The electricity demand is slightly lower than that on level 2, because less power needed in offices and school, while residential and retails stays nearly unchanged. The overall heating, cooling and DHW demands become less than that on level 2 since fewer occupants are expected at offices, school and retail shops. This shows that the electricity demand still influences mostly while the system energy demand is required less.

In the case of level 4 , citizens stay at home $24 \mathrm{~h}$ per day, while offices and school are empty. Only the retail shops are open but with the least occupancy density. Compared to the base case, the average Delivered electricity in the whole strict increases by $14.3 \%$, which contributed mostly by residential buildings and retail shops while offices and school are closed. In the contrast, the needs for heating/cooling and DHW drop respectively. The reasons are similar to previous scenarios. The average total system energy demand decreases by about $12.0 \%$. The increased amount of electricity demand is nearly equal to the drops of the system energy demands.

\subsection{Overall comparison and discussion}

Fig. 15 shows the variation of the average delivered electricity demand and the mean system energy demand in the base case and different confinement levels for one year duration. Comparing to level 1 (base case), the mean delivered electricity demand increases in range of $14.3 \%$ to $18.7 \%$, while the average system energy demand decreases in a range of $7.1 \%$ to $12.0 \%$. The stricter confinement measure leads to the lower increase percentage for the average delivered electricity demand, but higher decrease percentage in average system energy demand. In a 'soft' case as level 2 and 3, both schools and office buildings have to stay open,

Table 7

Simulation results of different confinement levels in one year duration.

\begin{tabular}{|c|c|c|c|c|c|c|c|c|}
\hline \multirow[t]{2}{*}{ Archetype } & $\begin{array}{l}\text { Lighting } \\
{\left[\mathrm{kWh} / \mathrm{m}^{2}\right]}\end{array}$ & $\begin{array}{l}\text { Equipment } \\
{\left[\mathrm{kWh} / \mathrm{m}^{2}\right]}\end{array}$ & $\begin{array}{l}\text { DHW } \\
{[\mathrm{kWh} /} \\
\left.\mathrm{m}^{2}\right]\end{array}$ & $\begin{array}{l}\text { Heating } \\
{\left[\mathrm{kWh} / \mathrm{m}^{2}\right]}\end{array}$ & $\begin{array}{l}\text { Cooling } \\
{\left[\mathrm{kWh} / \mathrm{m}^{2}\right]}\end{array}$ & $\begin{array}{l}\text { Delivered electricity } \\
\text { demand }\left[\mathrm{kWh} / \mathrm{m}^{2}\right]\end{array}$ & $\begin{array}{l}\text { System energy } \\
{\left[\mathrm{kWh} / \mathrm{m}^{2}\right]}\end{array}$ & $\begin{array}{l}\text { TOTAL energy demand } \\
{\left[\mathrm{kWh} / \mathrm{m}^{2}\right]}\end{array}$ \\
\hline & $0 ; 1$ & $0 ; 2$ & $0 ; 3$ & $0 ; 4$ & $0 ; 5$ & $0 ; 1+0 ; 2$ & $0 ; 3+0 ; 4+0 ; 5$ & $0_{; 1}+0_{; 2}+0_{; 3}+0_{; 4}+0_{; 5}$ \\
\hline \multicolumn{9}{|c|}{ Level 2 (Area weighted average approach : average values are calculated based on the respective area percentage of each archetype) } \\
\hline $\begin{array}{l}\text { Residential ( } 82.7 \% \\
\text { of total area) }\end{array}$ & 18,1 & 19,0 & 25,0 & 23,0 & 0,0 & 37,1 & 48,0 & 85,1 \\
\hline $\begin{array}{l}\text { School }(2.9 \% \text { of } \\
\text { total area) }\end{array}$ & 8,1 & 19,2 & 1,5 & 23,2 & 6,2 & 27,3 & 30,9 & 58,2 \\
\hline $\begin{array}{l}\text { Office ( } 8.1 \% \text { of total } \\
\text { area) }\end{array}$ & 10,9 & 19,0 & 1,5 & 23,6 & 5,6 & 29,9 & 30,7 & 60,6 \\
\hline $\begin{array}{l}\text { Retail shop ( } 6.3 \% \\
\text { of total area) }\end{array}$ & 39,1 & 34,2 & 1,5 & 1,1 & 19,2 & 73,3 & 21,9 & 95,1 \\
\hline $\begin{array}{l}\text { Area weighted } \\
\text { average }\end{array}$ & 18,6 & 20,0 & 20,9 & 21,7 & 1,8 & 38,5 & 44.4 & 82,9 \\
\hline \multicolumn{9}{|c|}{ Level 3 (Area weighted average approach : average values are calculated based on the respective area percentage of each archetype) } \\
\hline $\begin{array}{l}\text { Residential ( } 82.7 \% \\
\text { of total area) }\end{array}$ & 18,1 & 19,0 & 25,0 & 21,5 & 0,0 & 37,1 & 46,5 & 83,6 \\
\hline $\begin{array}{l}\text { School }(2.9 \% \text { of } \\
\text { total area })\end{array}$ & 7,2 & 16,8 & 1,0 & 25,4 & 5,1 & 24,1 & 31,4 & 55,5 \\
\hline $\begin{array}{l}\text { Office }(8.1 \% \text { of total } \\
\text { area) }\end{array}$ & 9,8 & 16,9 & 1,0 & 26,1 & 5,2 & 26,7 & 32,2 & 58,9 \\
\hline $\begin{array}{l}\text { Retail shop ( } 6.3 \% \\
\text { of total area) }\end{array}$ & 39,1 & 34,2 & 1,0 & 1,2 & 19,1 & 73,3 & 21,3 & 94,5 \\
\hline $\begin{array}{l}\text { Area weighted } \\
\text { average }\end{array}$ & 18,5 & 19,7 & 20,8 & 20,7 & 1,8 & 38,2 & 43.2 & 81,4 \\
\hline \multicolumn{9}{|c|}{ Level 4 (Area weighted average approach : average values are calculated based on the respective area percentage of each archetype) } \\
\hline $\begin{array}{l}\text { Residential ( } 82.7 \% \\
\text { of total area) }\end{array}$ & 18.1 & 19.0 & 25,0 & 19.9 & 0 & 37.1 & 44,9 & 82,0 \\
\hline $\begin{array}{l}\text { School }(2.9 \% \text { of } \\
\text { total area })\end{array}$ & 3.7 & 9.5 & 0,0 & 32.6 & 3.4 & 13.2 & 36,0 & 49,2 \\
\hline $\begin{array}{l}\text { Office }(8.1 \% \text { of total } \\
\text { area) }\end{array}$ & 6.4 & 10.6 & 0,0 & 32.4 & 4.2 & 17.0 & 36,7 & 53,7 \\
\hline $\begin{array}{l}\text { Retail shop ( } 6.3 \% \\
\text { of total area) }\end{array}$ & 39.1 & 34.2 & 1,0 & 1.2 & 19.0 & 73.3 & 21,2 & 94,4 \\
\hline $\begin{array}{l}\text { Area weighted } \\
\text { average }\end{array}$ & 18.1 & 19.0 & 20,7 & 20.1 & 1.6 & 37.1 & 42.5 & 79,5 \\
\hline
\end{tabular}




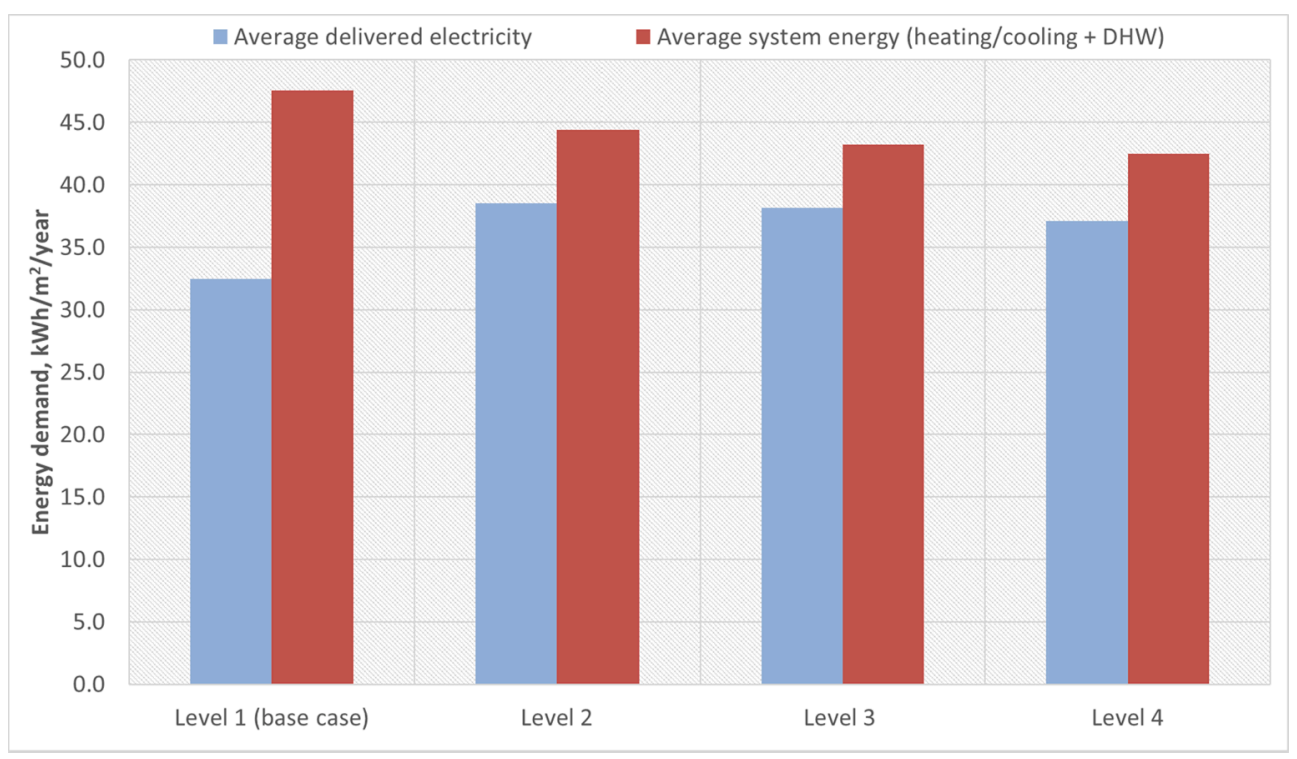

Fig. 15. Average Delivered electricity and system energy demands of the whole district at base case and confinement levels.

resulting in a larger electricity need in total. While in a fully 'lock-down' case as level 4, schools and offices are closed without any power consumption. So the overall electricity demand increases at a higher percentage when confinement measures are 'soft' in such a residential district. The system energy demands decreases with the tightness of confinement measures. When the lock-down ratio rises, less and less heating/cooling and DHW are required in offices, schools and retails. Meanwhile, although more DHW is needed in residential buildings, less heating is required due to more internal heat gains.

From Fig. 16, it is obvious that the electricity demand is higher in residential buildings and retail shops when confinement level increases, but school and offices need less electricity. These results are in line with the practice and assumptions. For instance, occupants need more electricity when they have to stay longer at home for living and working; retails require more power when they are assumed to open for longer time, in order to create opportunities for shopping peak shifting and social distance. Offices and school don't need so much electricity when they are close partially or fully.
In Fig. 17, the total system energy demands of each archetype at base case and different confinement levels are displayed. When the confinement becomes harder and harder, more and more internal heat gains from occupants, lighting and equipment can be expected in residential buildings, leading to a lower and lower heating need there. Although DHW and cooling demand increase, but their magnitude is much smaller than heating load. So the total system energy demand in residential buildings decreases when confinement level increases. School and office buildings vary oppositely as both school and offices need more heating due to less internal heat gains. Heating system has to stay open even when there is no occupant in offices and school, to ensure heathy indoor environment. So higher confinement level, more system energy demands are necessary in schools and offices. Retails shops need a bit more cooling in summer for longer opening, but they requires less heating meanwhile in winter when occupant density/ventilation is much smaller, causing a general drop in overall system energy load. However, this decrease percentage in retails seems very limited when the confinement level increases.

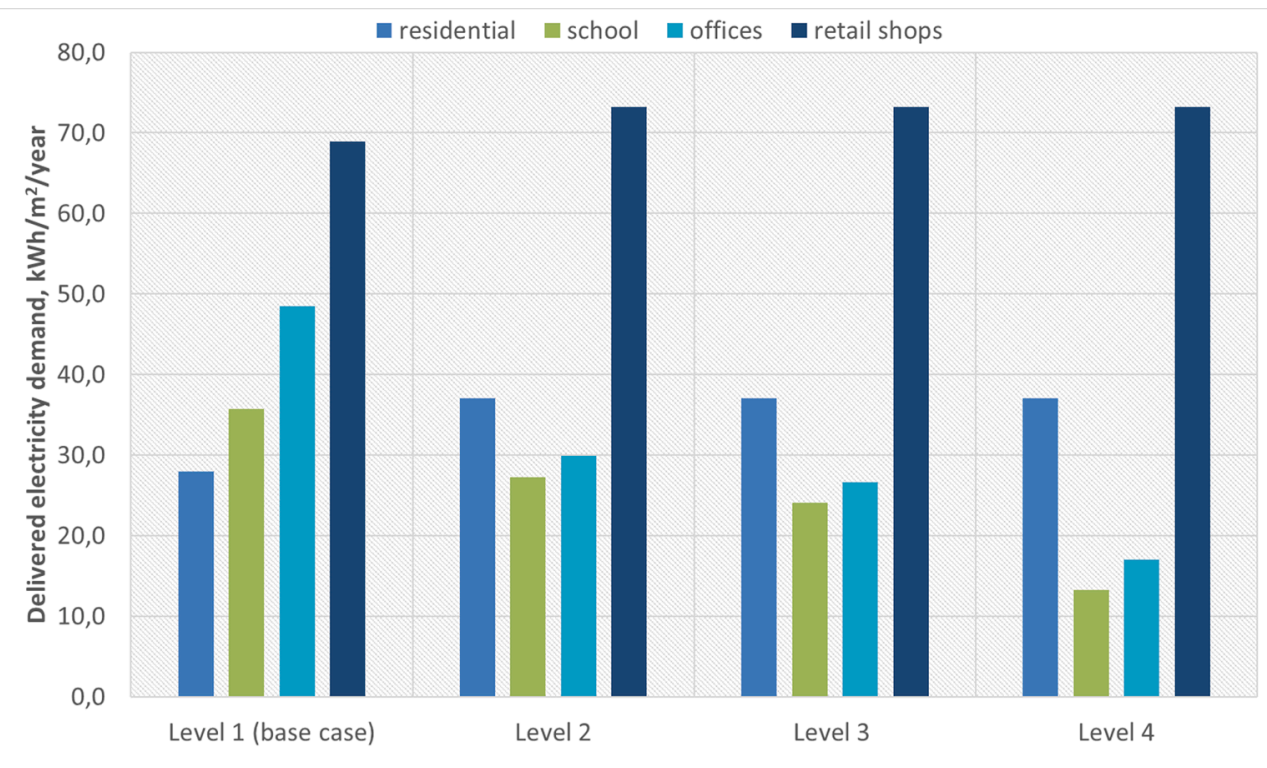

Fig. 16. Delivered electricity loads of each archetype at base case and confinement levels. 


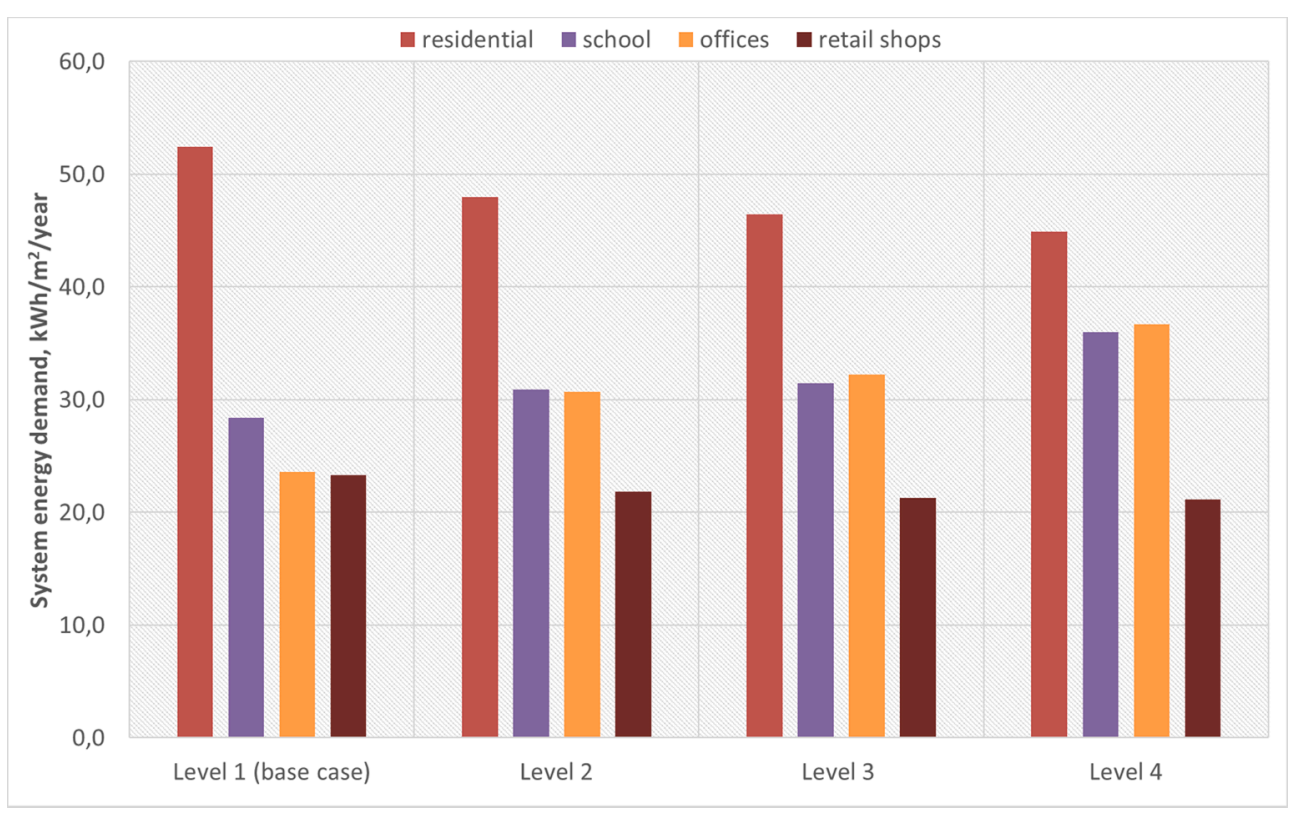

Fig. 17. Total system energy demands of each archetype at base case and confinement levels.

Fig. 18 demonstrates the variation of energy demand with month, including the total aggregated delivered electricity and the system energy loads for the whole district. In this way, it explicitly exhibits the detailed varying patterns at the base case and at different confinement levels across a whole year. All the delivered electricity demands have a relatively smooth annual variation. In the base case, the monthly total delivered electricity demand has sharp drops in February and August. It is found that there are two main factors that influences the monthly total delivered electricity demand: (1) number of days in a month, and (2) holidays. In February, the decrease in the total delivered electricity demand is mostly caused by the relatively smaller number of days in the months (i.e. 28 days as compared with 30 or 31 days in other months). In fact, compared with a month of 30 days, the decrease of days in February is about $6.7 \%$, while the approximate electricity demand reduction is about $7.7 \%$. It is also noticed that all the months with 30 days have lower delivered electricity demand than the others with 31 days, and February has only 28 days; so it is much lower. In addition, sport break usually takes place for one week in February and early November in Borlänge, and most family go out for sports holidays in the base case. This one-week sport break is another reason leading to decrease in the delivered electricity demand. Different from the summer holiday, only part of people with children usually take sport breaks. So the offices will keep open during the sport breaks, and only part residential buildings will have lower electricity demand in the base case. Therefore, the sport break has relatively smaller magnitude in electricity decrease than that of the day numbers. Thus, in the autumn, the impact of sport break on the demand decrease is not so significant, since the autumn sports break usually appears in early November with total 30 days in that month. So there is a different trend for the total aggregated electricity use in this two sport holiday periods. In the simulation, it assumes that most people take two weeks holidays in early August based on the local social custom in Borlänge city. Such long holiday will lead to significantly drops in electricity use at all types of buildings, due to closed offices/school and unoccupied residential buildings. In other confinement levels from level 2 to level 4, less outdoor holidays (such as sport breaks) are foreseen, comparing to that on the base case. In the simulation, during the holidays for the three confinement levels, it considers that most people will stay at home for longer time, without going out for sports activities. It is observed that the valleys of electricity demands are no longer in August, but electricity use in August is still relatively smaller, since offices and school will close for a short period during summer break. As a result, the aggregated electricity demand in August will be slightly lower than that in other months. While in February, as it has the least days in a month, the aggregated electricity demand is still much lower than that in the other months, even with less outdoor holidays, resulting in the lowest monthly electricity demands in all these three levels. It is obvious that the confinement measures lead to higher delivered electricity loads than the base case all year around. This is because, in all the three confinement levels, retails are assumed to open longer; and more importantly, more occupants will stay longer at home for living and working in the simulated one-year duration. These two changes result in larger needs in lighting and equipment in each month. In this district, residential buildings accounts for the largest proportion, so the total delivered electricity demand increase greatly in all the months, compared to the based case. However, by comparing level 2 to level 3 and 4, it is unsupervised that the higher level of confinement would not lead to higher delivered electricity. In level 2, school and office buildings have to be remained open, which have to consume electricity to maintain normal operation. In level 3, the open durations for school and offices are shorter than that in level 2, requiring less lighting and equipment power. In level 4, all school and offices are closed, and there is no electricity need any more. As the proportions of school and offices are not as large as that of residential buildings, such reduction in electricity need is not obvious in each month from level 2 to level 4.

In general, the system energy demands follow the principle trends for all 4 cases during a year, which have peak demands in winter and much lower demands in transit seasons and summer. In the winter, heating demand dominates while in the summer cooling needs become prominent. During transit seasons, both heating and cooling demands are little, resulting in the lowest system energy demand in September. These variations are also consistent with the monthly mean external air temperature, which achieves lowest in January and peaks in July. It is clear that confinement causes lower system energy loads than the base case, which are in proportional to confinement level in each month.

This research, as a preliminary study, is the first step to investigate the impact of COVID-19 on energy patterns and demands in different buildings at a district. Although it doesn't address the impact of the detailed occupant behavior change on energy demand, the initial findings at the aggregated level could help policy makers to understand the corresponding overall energy patterns, demand and impact on different seasons in each building type. It is then possible to have benchmark for setup of new building standard for extreme crisis, such as lighting/ 

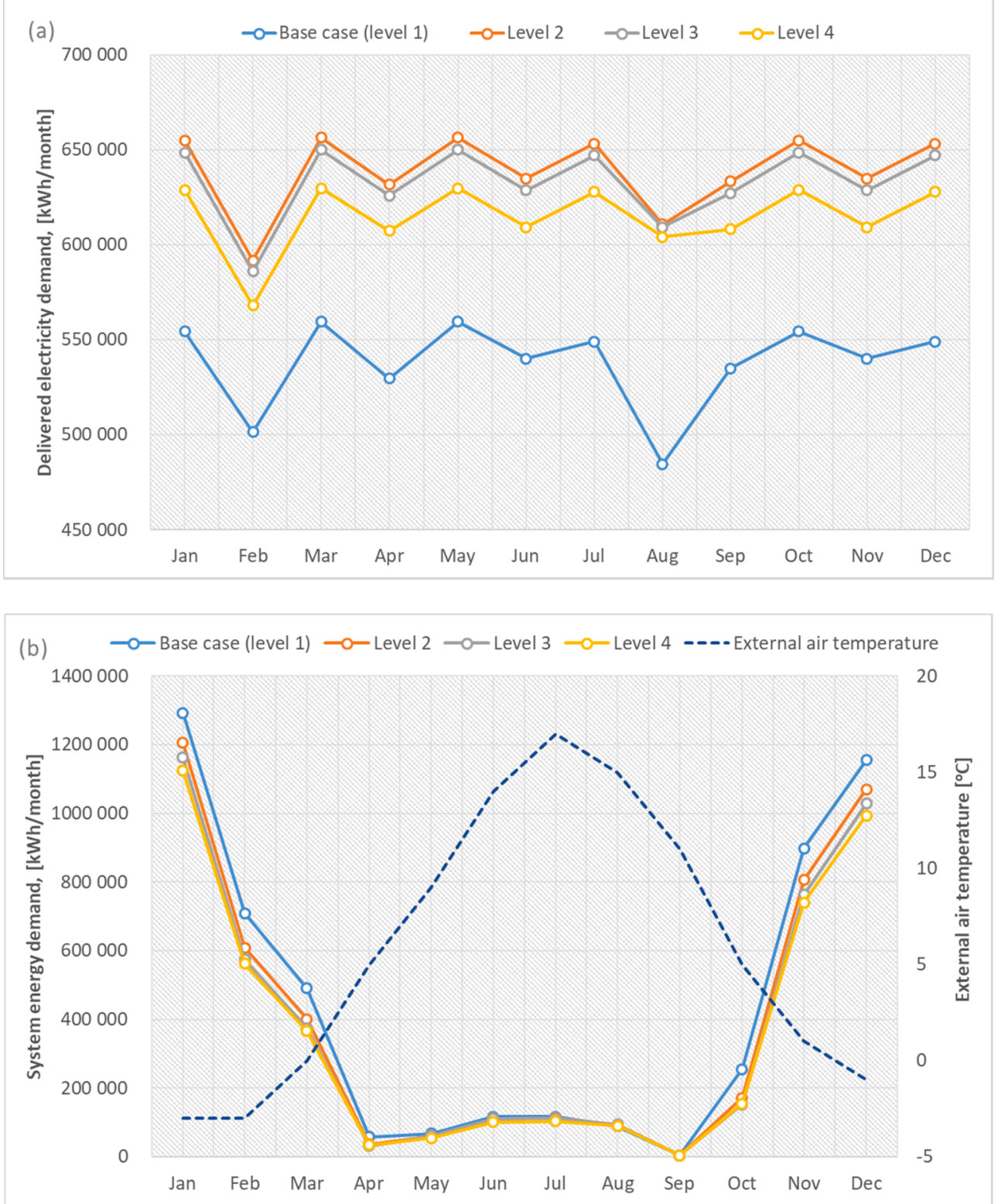

Fig. 18. Energy demands at base case and different confinement levels with months: (a) the delivered electricity variation; (b) the system energy variation.

equipment power density, ventilation rate and building design guidance. It is also useful for policy makers to trigger the discussion about sharing of energy cost in the mode of working from home. Moreover, it can support city-level or even regional-level policymaking in careful design of confinement measures, planning of new district and its energy supply system/infrastructure, as well as emergent operation of energy system to guarantee sufficient energy supply to different buildings.

By comparing Table 5 and Table 7, it is found that the increase or decrease in total energy demand of the whole district will be depending on the confinement level, determined by the net amount of the increased electricity need and the decreased system energy demands. Two 'soft' confinement scenarios lead to the increase in overall energy demand, while 'full lock down' scenario results in a slight lower total energy demand. So, it is not easy to say that a confinement measure will increase or decrease the overall energy consumptions, as it depends on the "functions" of the buildings in the district. There might be a different result in an industrial district or a commercial district. In addition, the change trend in energy demand may be different in another context or another country, where the regulations are different. As a result, more investigation should be done in particular context and the approach proposed in this paper can be replicated in different cases. Besides, discussions should be also carried out when considering energy demand on a system level, which should contain energy use in different sectors, such as building, transportation and industry.

\section{Limitations and future work}

This paper conducted a simulation study of a non-existing (virtual) neighborhood, which is still on the design and planning stage. As a result, there is no real data that can be used to validate the model. But we try to make sure the model as accurate as possible, by (1) using wellknown UMI tool, (2) relaying on reasonable assumptions, building regulations and statistics according to Swedish authority standards (for instance, SVEBY for residential building [17], school [18] and commercial building [19], and with recommendation from the national building standards BBR 26 and BFS 2016:12 BEN in Sweden [21,23]), as well as industry, and (3) a uncertain analysis of key input parameters and comparison with energy demand requirement in different 
standards. This paper's scope is limited to investigate the impact of different occupancy profiles (e.g. occupancy density and schedule), due to COVID-19, on energy demand. It relies on the existing building regulations, historical statistics and the assumed confinement measurements, owing to lacking of real data. The detailed occupancy behaviour changes (e.g. telecommuting scenarios) due to COVID-19 is not investigated as a result. For instance, it lacks data that describes how equipment (i.e. computers, TV etc) and lighting using in building changes with occupancy in such a pandemic. Meanwhile, this study has restricted impacts on delivered electricity loads based on the rigid assumptions of overall operation schedules, which are lacking of explicit social background knowledge. In the future, it is important to have the real measurement data for such detailed behavior change to benchmark the parameter setup in the simulation tool. In terms of more accurate community energy model results, it is also significant to fully obtain compulsory social background knowledge, for instance social customs, holiday mechanism and various operating modes of different functional institutions. These together will not only further help to improve the simulation accuracy, but also make recommendations for solid update of building regulation, especially for emergencies as COVID-19 pandemic.

On another hand, compared to standard method used in this study, energy demand usually have a different correlation with occupancy profile in different types of buildings. For instance, based occupancy estimation by mobile phone, energy consumption differs by $+1 \%$ to $15 \%$ for residential buildings and by $-4 \%$ to $-21 \%$ for commercial buildings, compared to standard methods [34]. In some buildings, even though the occupancy shows a significant correlation with the overall amount of electricity used, but it lacks correlation with the amount of cooling supplied by the HVAC system in campus buildings [35]. This is because commercial and non-residential buildings (especially larger, older constructions) are often monitored and controlled through a facilities provider, which reduces the direct feedback of information to building occupants. With large-scale HVAC systems, the focus is often placed on maintenance rather than a rapidly responsive system that can adjust in real time to varying levels of occupancy [35]. As a result, the standard approach in this study has its limitation, which might not be directly related to current benchmark classifications (i.e. office buildings). In the future, new models for occupancy and energy demand, such as $[34,36]$, will be needed for designers to utilize at the early design stage for more accurate estimation.

\section{Conclusion}

This paper evaluates the impact of the confined measures due to COVID-19 outbreak on the energy demand for a building mix in a 'virtual' district in Sweden, by proposing the dedicated occupancy schedules related to the different confinement scenarios.

In the level 1 (base case, normal life without confinement measure), the delivered electricity energy demand and the total system energy demand of the district are simulated at about $32.4 \mathrm{kWh} / \mathrm{m}^{2} /$ year and $47.6 \mathrm{kWh} / \mathrm{m}^{2} /$ year respectively in average, where retail shops have the highest energy demand due to the high needs in lighting and the equipment operation. Residential buildings rank the second since the heating demand and the DHW loads are high. Heating accounts for the largest proportion, which therefore dominates the variation trend of total energy demand with the months over a year.

Comparing to level 1 (base case), in the scenarios with different levels of containment measures, the Delivered electricity of the entire district increases in a range of $14.3 \%$ to $18.7 \%$, contributed mainly by residential buildings and retail shops. However, the mean system energy demands, such as heating, cooling, and domestic hot water, decreases in a range of $7.1 \%$ to $12.0 \%$. These two variation trends nearly cancel each other out, leaving the total energy demand almost unaffected in such a residential district within Swedish context. In addition, the delivered electricity demands in all the four cases have a relatively smooth variation across a year. The system energy demands follow the principle trends for all the four cases during a year, which have peak demands in winter and much lower demands in transit seasons and summer.

The increase or decrease in total energy demand of the whole district is depending on the confinement level, determined by the net amount of the increased electricity need and the decreased other demands. Two 'soft' confinement scenarios lead to the increase in overall energy demand, while the 'full lock down' scenario results in a slight lower total energy demand. Therefore, it will be partial to say that a confinement measure will increase or decrease the overall energy consumptions, as it depends on the "functions" of the buildings in the district. There might be a different result in a different building district, such as an industrial district or a commercial district. A single district cannot reflect the overall influence of the COVID-19 on the whole energy system. In addition, the energy demand may change differently in another context or another country, where the regulations are different. As a result, more investigation should be done in particular context and the approach proposed in this paper can be replicated in different cases. Besides, a comprehensive discussion should be also conducted when considering energy demand on a system level, which include energy use in building, transportation and industry.

This paper's scope is limited to investigate the impact of different occupancy profiles (e.g. occupancy density and schedule), due to COVID-19, on energy demand. It relies on the existing building regulations, historical statistics and the assumed confinement measurements, owing to lacking of real data. The detailed occupancy behaviour changes (e.g. telecommuting scenarios) due to COVID-19 is not investigated. In the future, it is important to have the real measurement data for such detailed behavior change to benchmark the parameter setup in the simulation tool for the improved accuracy. It is also significant to fully obtain compulsory social background knowledge, for instance social customs, holiday mechanism and various operating modes of different functional institutions.

There might be a few more waves of COVID-19 outbreak, which may lead to different levels of closures. The corresponding impacts on Swedish or global energy demands in different types of districts and sectors are necessary to be carried on. It is expected that this research opens up such initiative by conducting a preliminary study in a residential district through simulation. These initial findings will help mitigate the influence from COVID-19 with appropriate prepreparations for new policy designs that can withstand future longterm shocks. The research results will help policy makers to understand the corresponding energy patterns and performance in different seasons. It is then possible to have benchmark for setup of new building standard for extreme crisis, such as lighting/equipment power density, ventilation rate and building design guidance. It is also useful for policy makers to trigger the discussion about sharing of energy cost in the mode of working from home. Moreover, it can support city-level or even regional-level policymaking in design of confinement measures, planning of new district and its energy supply system/infrastructure, as well as emergent operation of energy system to guarantee sufficient energy supply to different buildings.

\section{CRediT authorship contribution statement}

Xingxing Zhang: Conceptualization, Formal analysis, Investigation, Writing - original draft. Filippo Pellegrino: Methodology, Formal analysis, Investigation, Writing - original draft. Jingchun Shen: Methodology, Formal analysis, Investigation, Writing - original draft. Benedetta Copertaro: Writing - review \& editing. Pei Huang: Writing review \& editing. Puneet Kumar Saini: Methodology, Writing - review \& editing. Marco Lovati: Writing - review \& editing.

\section{Declaration of Competing Interest}

The authors declare that they have no known competing financial interests or personal relationships that could have appeared to influence 
the work reported in this paper.

\section{Acknowledgement}

This study was performed within the research project "ActivityBased Urban Building and Mobility Energy Modelling (UBMEM) for Planning of Future Cities", as part of the strategic innovation programme - Viable Cities, which is financed by the Swedish Energy Agency, VINNOVA and Formas. The authors appreciate the colleagues Annika Lind and Sara Keisu from WSP company for their suggestions in parameters setup and assumptions in the simulation.

\section{References}

[1] Qarnain Syed Shuibul, Muthuvel S, Bathrinath S. Review on government action plans to reduce energy consumption in buildings amid COVID-19 pandemic outbreak. Mater Today: Proc 2020. https://doi.org/10.1016/j.matpr.2020.04.723.

[2] Steffen Bjarne, Egli Florian, Pahle Michael, Schmidt Tobias S. Navigating the Clean Energy Transition in the COVID-19 Crisis. Joule 2020. https://doi.org/10.1016/j. joule.2020.04.011.

[3] Dabas C, European power demand falls below five-year average amid Covid-19 outbreak, [Online] https://www.energylivenews.com/2020/04/17/europeanpower-demand-falls-below-five-year-average-amid-covid-19-outbreak/ Accessed on 2020-05-25.

[4] Mylenka T, Impact of Covid-19 on the global energy sector, [Online] https://www. pv-magazine.com/2020/04/24/impact-of-covid-19-on-the-global-energy-sector/ Accessed on 2020-05-22.

[5] Mcwilliams B And Zachmann G, Covid-19 crisis: electricity demand as a real-time indicator, [Online] https://www.bruegel.org/2020/03/covid-19-crisis-electricitydemand-as-a-real-time-indicator/ Accessed on 2020-05-22.

[6] Abbasabadi Narjes, Ashayeri Mehdi. Urban energy use modeling methods and tools: A review and an outlook. Build Environ 2019;161:106270.

[7] Zhang Xingxing, Lovati Marco, Vigna Ilaria, Widén Joakim, Han Mengjie, Gal Csilla, et al. A review of urban energy systems at building cluster level incorporating renewable-energy-source (RES) envelope solutions. Appl Energy 2018;230:1034-56.

[8] Christoph F Reinhart, Timur Dogan, J Alstan Jakubiec, Tarek Rakha and Andrew Sang, Proceedings of BS2013: 13th Conference of International Building Performance Simulation Association, Chambéry, France, August 26-28.

[9] Mastropietro P, Rodilla P, Batlle C, Measures to tackle the Covid-19 outbreak impact on energy poverty: Preliminary analysis based on the Italian and Spanish experiences, [Online] https://fsr.eui.eu/measures-to-tackle-the-covid-19-outbreakimpact-on-energy-poverty/ Accessed on 2020-05-22.

[10] Widén Joakim, Wäckelgărd Ewa. A high-resolution stochastic model of domestic activity patterns and electricity demand. Appl Energy 2010;87:1880-92.

[11] J. Widén, A. Nilsson, E. WäckelgårdA combined Markov-chain and bottom-up approach to modelling of domestic lighting demand Energy Build 2009, Volume 41, 1001-1012.

[12] I. Richardson, M. Thomson, D. Infield A high-resolution domestic building occupancy model for energy demand simulations, Energy and Building 2008 , Volume 40, 1560-1566.

[13] Barthelmes Verena M, Li Rongling, Andersen Rune K, Bahnfleth William, Corgnati Stefano P, Rode Carsten. Profiling occupant behaviour in Danish dwellings using time use survey data. Energy Build 2018;177:329-40.

[14] Lee S, Chong WO, Chou J-S. Examining the Relationships between Stationary Occupancy and Building Energy Loads in US Educational Buildings-Case Study. Sustainability 2020;12:893.

[15] Hampton Sam. An ethnography of energy demand and working from home: Exploring the affective dimensions of social practice in the United Kingdom. Energy Res Social Sci 2017;28:1-10.
[16] Cerqueira Eugênia Dória Viana, Motte-Baumvol Benjamin. Leslie Belton Chevallier, Olivier Bonin, Does working from home reduce CO2 emissions? An analysis of travel patterns as dictated by workplaces, Transportation Research Part D: Transport and Environment 2020;83:102338.

[17] SVEBY, Brukarindata bostäder (User data for house), [Online] http://www.sveby. org/wp-content/uploads/2012/10/Sveby_Brukarindata_bostader_version_1.0.pdf accessed on May 25th, 2020.

[18] SVEBY, Brukarindata undervisningsbyggnader (user data for educational building), [Online] http://www.sveby.org/wp-content/uploads/2016/05/SvebyBrukarindata-undervisning-1.0-160525.pdf Accessed on 2020-05-25.

[19] SVEBY, Brukarindata kontor (user data for office), [Online] http://www.sveby. org/wp-content/uploads/2013/06/Brukarindata-kontor-version-1.1.pdf Accessed on 2020 05-25.

[20] Borlänge kommun, Planprogram Jakobsgårdarna approval Document, The social housing sector, the land and land office, 2017.

[21] Boverket's building regulations (BBR 26): [Online] https://www.boverket.se/en/ start/building-in-sweden/swedish-market/laws-and-regulations/nationalregulations/building-regulations/ Accessed on 2020-05-25.

[22] SVEBY, Klimatdatafiler för 2019 för alla 310 orterna från SMHI, [Online] https:// rinfo.boverket.se/BEN/PDF/BFS2016-12-BEN-1-r\%C3\%A4ttelseblad.pdf Accessed on 2020-07-20.

[23] Yvonne Svensson, Boverkets föreskrifter och allmänna råd om fastställande av byggnadens energianvändning vid normalt brukande och ett normalår (BFS 2016: 12 BEN1), Nov. 2016, [Online] https://rinfo.boverket.se/BEN/PDF/BFS2016-12BEN-1-r\%C3\%A4ttelseblad.pdf Accessed on 2020-07-20.

[24] Bäck Jakob. The Internet helps you work from home. The Internet Foundation. [Online] 2020. Accessed on 2020-06-22.

[25] Statista 2020. Share of the enterprises with home office in Sweden from 2009 to 2018. [Online] https://www.statista.com/statistics/545241/sweden-enterpriseswith-home-workers/ Accessed on 2020-06-29.

[26] Goia Francesco. Search for the optimal window-to-wall ratio in office buildings in different European climates and the implications on total energy saving potential. Sol Energy 2016;132:467-92.

[27] Levin P. (edit), Brukarindata för energiberäkningar i bostäder, Svebyprogrammet, projektrapport, Apr. 2009, Standardisera och verifiera energiprestanda i byggnader (SVEBY), [Online] http://www.sveby.org/wp-content/uploads/2011/06/ brukarindata_bostader.pdf Accessed on 2020-07-22.

[28] Ellegård, Kajsa, 2002, Lockropen ljuder: Kom hem, I: E Amnå \& L Ilshammar (red) Den gränslösa medborgaren. En antologi om en möjlig dialog, Agora Stockholm, sid119-148.

[29] Elmroth A. Energihushållning och värmeisolering. Byggvägledning 8. Stockholm: Svensk Byggtjänst; 2007.

[30] Levin P. (edit), Brukarindata kontor, Svebyprogrammet, Version 1.1, Jun. 2013, Standardisera och verifiera energiprestanda i byggnader (SVEBY), [Online] http:// www.sveby.org/wp-content/uploads/2013/06/Brukarindata-kontor-version-1.1. pdf Accessed on 2020-07-22.

[31] Hiller, C., 2007, "Hållbar energianvändning i småhus - etapp II" (pågående doktorandprojekt vid SP Sveriges Tekniska Forskningsinstitut och Lunds Tekniska Högskola).

[32] FEBY, 2018. Specification for zero energy, passive and low-energy houses.

[33] Sweden Green Building Council, Miljöbyggnad certification. [Online] https:// www.sgbc.se/certifiering/miljobyggnad/ Access on 2020-07-25.

[34] E Barbour, C Davila Cerezo, S Gupta, C Reinhart, J Kaur and M Gonzalez, Planning for sustainable cities by estimating building occupancy with mobile phones, Nature Communications, 10, Article number: 3736, 2019.

[35] Martani C, Lee D, Robinson P, Britter R, Ratti C. ENERNET: Studying the dynamic relationship between building occupancy and energy consumption. Energy Build 2012;47:584-91.

[36] Menezes AC, Cripps A, Buswell RA, Wright J, Bouchlaghem D. Estimating the energy consumption and power demand of small power equipment in office buildings. Energy Build 2014;75:199-209. 